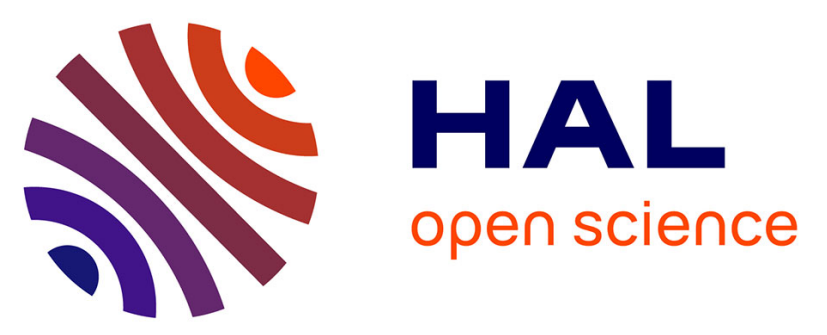

\title{
Three-dimensional modeling of the Gulf of Lion's hydrodynamics (northwest Mediterranean) during January 1999 (MOOGLI3 Experiment) and late winter 1999: Western Mediterranean Intermediate Water's (WIW's) formation and its cascading over the shelf break
}

Claire Dufau-Julliand, Patrick Marsaleix, Anne Petrenko, I. Dekeyser

\section{- To cite this version:}

Claire Dufau-Julliand, Patrick Marsaleix, Anne Petrenko, I. Dekeyser. Three-dimensional modeling of the Gulf of Lion's hydrodynamics (northwest Mediterranean) during January 1999 (MOOGLI3 Experiment) and late winter 1999: Western Mediterranean Intermediate Water's (WIW's) formation and its cascading over the shelf break. Journal of Geophysical Research, 2004, 109 (C11), pp.C11002. 10.1029/2003JC002019 . hal-02110264

\author{
HAL Id: hal-02110264 \\ https://hal.science/hal-02110264
}

Submitted on 29 Jan 2021

HAL is a multi-disciplinary open access archive for the deposit and dissemination of scientific research documents, whether they are published or not. The documents may come from teaching and research institutions in France or abroad, or from public or private research centers.
L'archive ouverte pluridisciplinaire HAL, est destinée au dépôt et à la diffusion de documents scientifiques de niveau recherche, publiés ou non, émanant des établissements d'enseignement et de recherche français ou étrangers, des laboratoires publics ou privés. 


\title{
Three-dimensional modeling of the Gulf of Lion's hydrodynamics (northwest Mediterranean) during January 1999 (MOOGLI3 Experiment) and late winter 1999: Western Mediterranean Intermediate Water's (WIW's) formation and its cascading over the shelf break
}

\author{
Claire Dufau-Julliand ${ }^{1}$ and Patrick Marsaleix \\ Laboratoire d'Aérologie—Pôle d'Océanographie Côtière, Toulouse, France
}

Anne Petrenko and Ivan Dekeyser

Centre d'Océanologie de Marseille, Université de la Méditerranée, Campus de Luminy, Marseille, France

Received 26 June 2003; revised 21 June 2004; accepted 30 July 2004; published 4 November 2004.

[1] The Gulf of Lion's hydrodynamics are investigated with a numerical simulation of the 1998-1999 winter, performed with a three-dimensional (3-D) free-surface model and real forcings. The model initial state derives from the large-scale outputs of the MOM $\left(1 / 8^{\circ}\right)$ using a specific initialization method. The model results are validated with an oceanographic data set collected in the gulf during the MOOGLI3 cruise (11-21 January 1999). The modeled outputs agree well with the main hydrological and circulation patterns observed during MOOGLI3. The study focuses on a strong and peculiar event of dense water (Western Mediterranean Intermediate Water (WIW)) formation on the continental shelf and its cascading over the shelf break. This latter was detected by a steep temperature decrease in the time series of a mooring line in the nearby Lacaze-Duthiers canyon which is well reproduced in the simulation. Modeled dense plumes appear during the MOOGLI3 period but more especially during late winter. Shapiro's theory of dense plume propagating on a sloping bottom is applied and provides information of the plume driving mechanisms. In both cases of plume studied, friction effects and Ekman drainage by the ambient current explain only a part of the plume motion. The complementary forcing is probably the steep local bathymetry irregularities. This 3-D simulation permits also to evaluate the total amount of WIW formed during the 1998-1999 winter over the Gulf of Lion's shelf to $500 \mathrm{~km}^{3}$. INDEX TERMS: 4219 Oceanography: General: Continental shelf processes; 4283 Oceanography: General: Water masses; 4512 Oceanography: Physical: Currents; 9335 Information Related to Geographic Region: Europe; KEYWORDS: 3-D modeling, cascading of dense water, northwest Mediterranean

Citation: Dufau-Julliand, C., P. Marsaleix, A. Petrenko, and I. Dekeyser (2004), Three-dimensional modeling of the Gulf of Lion's hydrodynamics (northwest Mediterranean) during January 1999 (MOOGLI3 Experiment) and late winter 1999: Western Mediterranean Intermediate Water's (WIW's) formation and its cascading over the shelf break, J. Geophys. Res., 109, C11002, doi:10.1029/2003JC002019.

\section{Introduction}

[2] As put forward by Hill [1998], coastal problems deal nowadays with a better understanding of the physical environment of the marine ecosystems, which are jeopardized by growing human activities along the coasts. In coastal ocean, typical dynamic processes differ markedly from those of the deep ocean. The presence of coasts and the relatively shallow depths constitute the main constraints of these areas.

\footnotetext{
${ }^{1}$ Also at Centre d'Océanologie de Marseille, Université de la Méditerranée, Campus de Luminy, Marseille, France.

Copyright 2004 by the American Geophysical Union. 0148-0227/04/2003JC002019
}

Surface effects such as wind stress or buoyancy inputs, positive with freshwater discharge or negative with surface cooling in winter, can then extend to a large part of the water column [Csanady, 1982]. In no-tidal seas, such as the Gulf of Lion (hereinafter GoL), these effects are of particularly great influence. The coastal water masses have consequently very special winter properties such as weak salinity, low temperature, and strong concentration in particulate matter. At the shelf edge, numerous processes induce cross-slope exchange [Huthnance, 1995]: among others, slope currents (meandering), wind effects (upwelling), and fronts, but also cascading of dense waters by gravity forces.

[3] Located at the northwestern part of the Mediterranean Sea, the GoL can be classified as a coastal area in regard with its wide semicircular sloping continental shelf (mean 


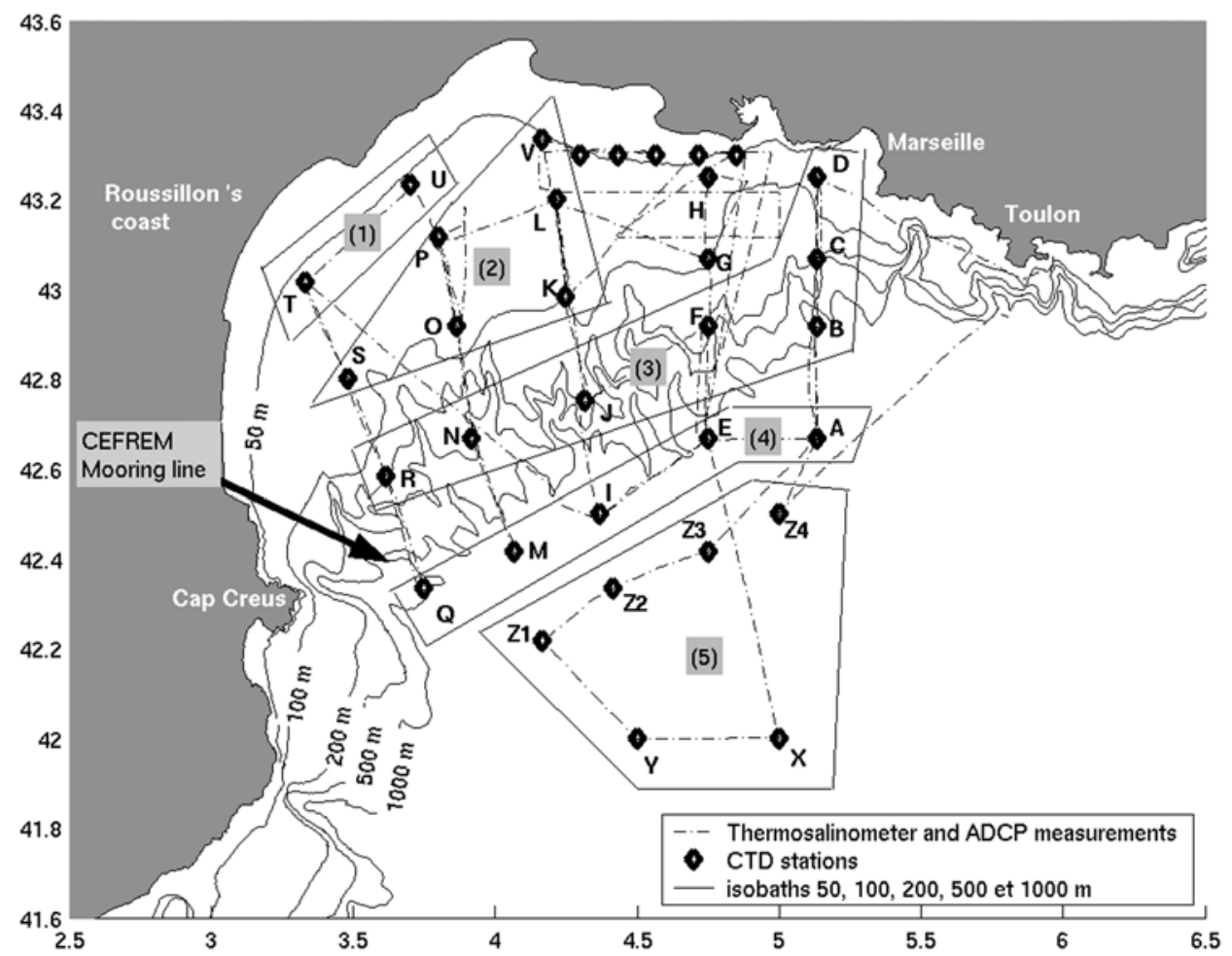

Figure 1. The Gulf of Lion's topography and the description of MOOGLI3 experiment (11-21 January 1999): track of the ship in dash-dotted black line and CTD stations in solid diamonds with their corresponding letter. The boxes separate the CTD classification into five areas.

depth of $50 \mathrm{~m}$ ) followed by an abrupt shelf edge with a varying slope and numerous submarine canyons (Figure 1). An intense atmospheric forcing occurs there: Strong winds, Tramontane and Mistral, blow regularly during the winter from north/northwest, bringing cold and dry atmospheric conditions. When they are associated with strong negative heat fluxes (during cold winters), they generate dense water (Winter Mediterranean Intermediate Water, hereinafter WIW) above the continental shelf [Fieux, 1974]. This WIW differs from the Winter Mediterranean Dense Water (WMDW), which is formed in the open ocean of the GoL under the same strong atmospheric conditions. WIW's temperature is indeed lower than $12^{\circ} \mathrm{C}$, and its salinity is lower than 37.9, whereas WMDW's characteristics are, respectively, $12.8^{\circ} \mathrm{C}$ and 38.4. Freshwater inputs are also an important feature of the GoL. The Rhône river mouth is located at the northeastern part of the continental shelf. With a mean water discharge of $1700 \mathrm{~m}^{3} / \mathrm{s}$ [Thill et al., 2001], this river represents the major input of freshwater of the western Mediterranean Sea. Beyond its mouth, a freshwater plume is formed flowing over salt water. Previous studies have shown that the plume extension and its shape depend strongly on the wind and surrounding circulation [Estournel et al., 1997; Marsaleix et al., 1998]. Finally, a general circulation influences the GoL: the Northern Current (hereinafter NC), which flows from the Ligurian Sea to the Catalan Sea along the continental slope. Its core is several hundred meters deep, and its position and flux vary all year round [Conan and Millot, 1995; Sammari et al., 1995; Bethoux et al., 1988; Lapouyade and Durrieu de Madron, 2001; Petrenko, 2003].
[4] As shown above, dynamics of the GoL have been relatively quite investigated and described. Nevertheless, some processes are not yet entirely understood, such as the WIW formation during extreme winters. The MOOGLI3 experiment, made in January 1999 by the French Programme National d'Environnement Côtier, highlights the occurrence of WIW formation during this winter [Petrenko, 2003]. Furthermore, in a southwestern canyon, measurements of temperature also show cascading of WIW at mid-February 1999. This paper aims at studying numerically this phenomenon. First, a description of the modeling strategy is made in section 1 . Section 2 gives an overview from the available observations of the GoL's hydrodynamics during 1998-1999 wintertime. Section 3 focuses on the modeling validation. In section 4, atmospheric conditions for WIW formation and WIW formation in 1999 are investigated. The spreading of WIW over the continental shelf and shelf break are presented in section 5. Rather than gathering all the discussions at the end, it was found beneficial to separate them in each section.

\section{Modeling Strategy}

[5] The three-dimensional primitive equation coastal ocean model SYMPHONIE, used in this study, was previously described by Estournel et al. [1997]. SYMPHONIE results have already provided insight on the wind-induced circulation in the GoL [Estournel et al., 2003; Auclair et al., 2003], the intrusion of the $\mathrm{NC}$ on the shelf [Auclair et al., 2001] and the Rhône river plume [Estournel et al., 2001; Marsaleix et al., 1998]. 
[6] The three components of the current velocity, the free-surface elevation, temperature, and salinity are computed on a staggered C-grid [Arakawa and Suarez, 1983]. A generalized topography following coordinate system with 25 levels [Pietrzak et al., 2002] is used. The turbulence closure scheme consists in a prognostic equation for the turbulent kinetic energy combined with an algebraic formulation of the mixing and dissipation length [Bougeault and Lacarrere, 1989; Gaspar et al., 1990; Caniaux et al., 1993]. A leapfrog scheme is used for the time stepping. Following Blumberg and Mellor [1987], a time splitting technique permits us to compute the vertical shear of the current and its depth-averaged component separately with appropriate time steps. The horizontal mesh is $3 \mathrm{~km}$. The main boundary of the modeling domain has been chosen to be parallel to the continental slope (see Figure A1 in Appendix A).

[7] At the seafloor, the near-bottom stress $\left(\vec{\tau}_{\mathrm{b}}\right)$ is related to the horizontal bottom velocity $\left(\overrightarrow{\mathrm{V}}_{\mathrm{b}}\right)$ with a quadratic equation $\vec{\tau}_{\mathrm{b}}=\rho_{0} \mathrm{C}_{\mathrm{d}}\left\|\overrightarrow{\mathrm{V}}_{\mathrm{b}}\right\| \overrightarrow{\mathrm{V}}_{\mathrm{b}}$, where $C_{d}$ is the drag coefficient, parameterized by a logarithmic law of the vertical distance to the bottom [Blumberg and Mellor, 1987], with a roughness length of $10^{-2} \mathrm{~m}$. Heat and salinity fluxes are considered to be zero at this boundary. Concerning the flux of turbulent kinetic energy, the usual boundary layer balance between production and dissipation is applied (see discussion in work of Craig and Banner [1994]).

[8] At the surface, the momentum flux is equal to the wind stress. The heat flux results from the atmospheric fluxes (sensible and latent heat fluxes) and from the radiative fluxes (both short and long wavelengths). The salinity flux is calculated from evaporation. The flux of turbulent kinetic energy is parameterized similarly as the one at the bottom boundary. The wind stress and the sensible and latent heat fluxes are computed thanks to a bulk formula parameterization [Geernaert, 1990]. The formula associate sea surface temperature, computed by the ocean model, with the meteorological surface parameters: wind velocities $(10 \mathrm{~m}$ above the surface), humidity ( $2 \mathrm{~m}$ above the surface), temperature $(2 \mathrm{~m}$ above the surface), and sea surface pressure. These meteorological data are the instantaneous 3-hours outputs of the weather-forecast model Aladin (Meteo-France). The Aladin grid dimension is $0.1^{\circ}$ by $0.1^{\circ}$; each parameter is then interpolated on the grid of the ocean model. A time linear interpolation is also performed between two successive Aladin outputs. The radiative fluxes, directly given by the atmospheric model Aladin, are not instantaneous fields but are integrated over 3 hours.

[9] At open lateral boundaries, the free-surface elevation, $\eta$, and the component of transport orthogonal to the boundary, $U$, are given by the radiation condition of Oey and Chen [1992]: $\mathrm{U}=\mathrm{U}_{0} \pm \sqrt{\mathrm{gH}}\left(\eta-\eta_{0}\right)$. Other variables are given by $\nabla_{\mathrm{H}} \varphi=\nabla_{\mathrm{H}} \varphi_{0}$, where $\varphi$ stands for the tangential component of the depth-averaged current and baroclinic velocities. $\mathrm{U}_{0}, \varphi_{0}$, and $\eta_{0}$ refer to the large-scale field forcing. Concerning temperature and salinity, an upstream condition implies that large-scale fields, $T_{0}(\mathrm{t})$ and $S_{0}(\mathrm{t})$, are advected into the simulated domain under inflow conditions. The large-scale fields are also applied over the whole grid at $\mathrm{t}=t_{0}$ (initialization), i.e., on 15 December 1998.
[10] This initial state aims to start the simulation with the large-scale geostrophic circulation of the Gulf of Lion, generally identified as the Northern Current [Millot, 1990]. Recently, Estournel et al. [2003] proposed an original method allowing initializing of a coastal ocean model with complex three-dimensional currents adjusted to bathymetry constraints. This method, based on a linearized derivation of the external mode equations of the model, was applied here to start the simulations with a fully established NC. For the sake of the present study, some developments are added to the method originally proposed by Estournel et al. [2003]. The principal steps of the method and its recent developments are presented in Appendix A.

[11] Concerning the buoyancy inputs, the four major rivers of the Gulf of Lion (Rhône, Aude, Herault, and Orb) are taken into account for the freshwater supply. The Rhône is the most important one; its discharge represents more than $90 \%$ of the total freshwater inputs for the considered period. In the modeling, forcing is completed with its real flow measured every 3 hours by the "Compagnie du Rhône" in Beaucaire (a 70-km-upstream city). For the three others rivers, we used the daily flows provided by the" Direction Régionale de l'Environnement" (DIREN) of the Languedoc-Roussillon. The freshwater temperature of each river is set in the model to $8^{\circ} \mathrm{C}$. This value agrees with the Rhône's temperature pattern evidenced by Poirel et al. [2001] for the 1977-1999 period. Indeed, during winter months, the observed mean temperature was about $7^{\circ} \mathrm{C}$ at Saint-Alban (France). Saint-Alban is an upstream city $(240 \mathrm{~km})$ and the warming of the river waters between this city and the river mouth is estimated to about $1^{\circ} \mathrm{C}$ [from Poirel et al., 2001].

\section{Observations Made During Wintertime 1998-1999}

\subsection{MOOGLI3's Data Set}

[12] The MOOGLI3 experiment took place from 11 to 21 January 1999. This oceanographic cruise corresponded to the winter cruise of the original plan to collect data during the four seasons in the GoL [Raimbault, 2000]. Two kinds of data are available: (1) continuous measurements along the track of the vessel (Figure 1, dash-dotted line), consisting in horizontal currents (ADCP) measured every $8 \mathrm{~m}$ down to $400 \mathrm{~m}$, and sea surface temperature and salinity (thermosalinometer), (2) hydrologic profiles (CTD and Niskin samples) collected at stations (Figure 1, diamond patterns). A complete description of the observations made during the cruise is provided by Petrenko [2003]. The author points out the presence of relative WIW on the western part of the continental shelf in mid-January.

\subsection{Temperature and Currents Measurements in the Lacaze-Duthiers Canyon}

[13] From October 1993 to April 2000, a mooring with Aanderaa current meters was deployed by the "Centre de Formation et de Recherche sur l'Environnement Marin" (CEFREM) in the Lacaze-Duthiers canyon (western part of the GoL, Figure 1). The instruments measured current speed and direction as well as temperature (accuracy $\pm 0.2^{\circ} \mathrm{C}$ ) at mid-depth $(500 \mathrm{~m})$ and $30 \mathrm{~m}$ above the bottom $(990 \mathrm{~m})$. At the Lacaze-Duthiers mooring, cascading of cold waters, 

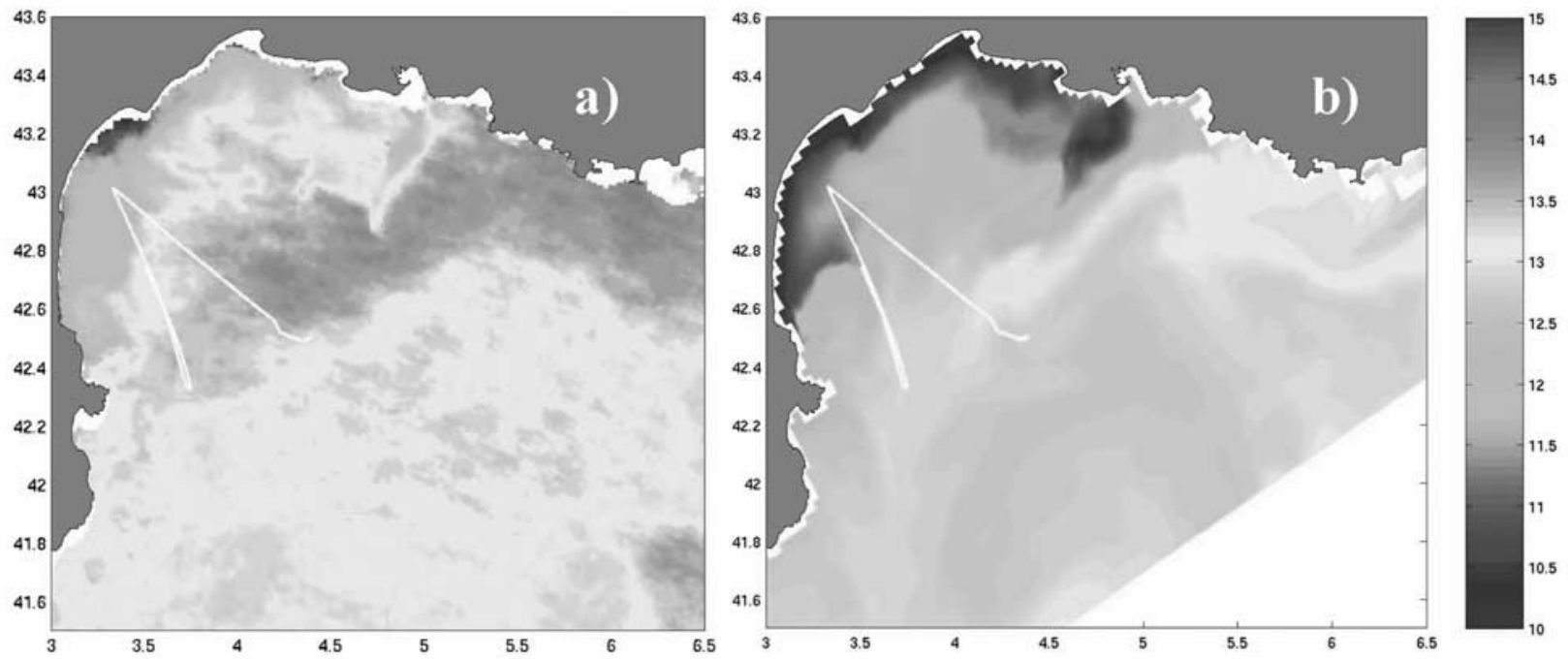

Figures 2a-2b. (a) AHRR sea surface temperature at 0000 hours on the 15 January 1999 (the white line corresponds to the trajectory of the vessel during 24 hours, 12 hours before and after this date). (b) Modeled sea surface temperature by SYMPHONIE at the same time. See color version of this figure at back of this issue.

detected by a strong cooling $\left(1^{\circ} \mathrm{C}\right)$ and down-canyon current (until $60 \mathrm{~cm} / \mathrm{s}$ at the end of February), took place from February 14 to March 12 [Bethoux et al., 2002, Figure 6]. Such an event had not been observed for the last 5 years.

\subsection{Available SST Satellite Images}

[14] Several daily composite Advanced Very High Resolution Radiometer (AVHRR) Sea Surface Temperature (SST) images are available for the Mediterranean Sea in winter 1999 on the Deutsch zentrum für Luft-and Raumfahrt (DLR) website. Those images give a synoptic view of the superficial thermal structure in the GoL and of its temporal evolution during the MOOGLI3 cruise (Figure 2a). The AVHRR SST is compared with the surface temperature measured on the ship during the experiment with a thermosalinograph (Figure 2c). This comparison shows a very good agreement between the two SSTs. It allows being confident in the quantitative information given by the satellite images.

\section{Validation of the Modeling}

[15] Since the model does not assimilate data, the simulation may not reproduce correctly some dynamical aspects of the GoL even with a realistic forcing. Therefore the

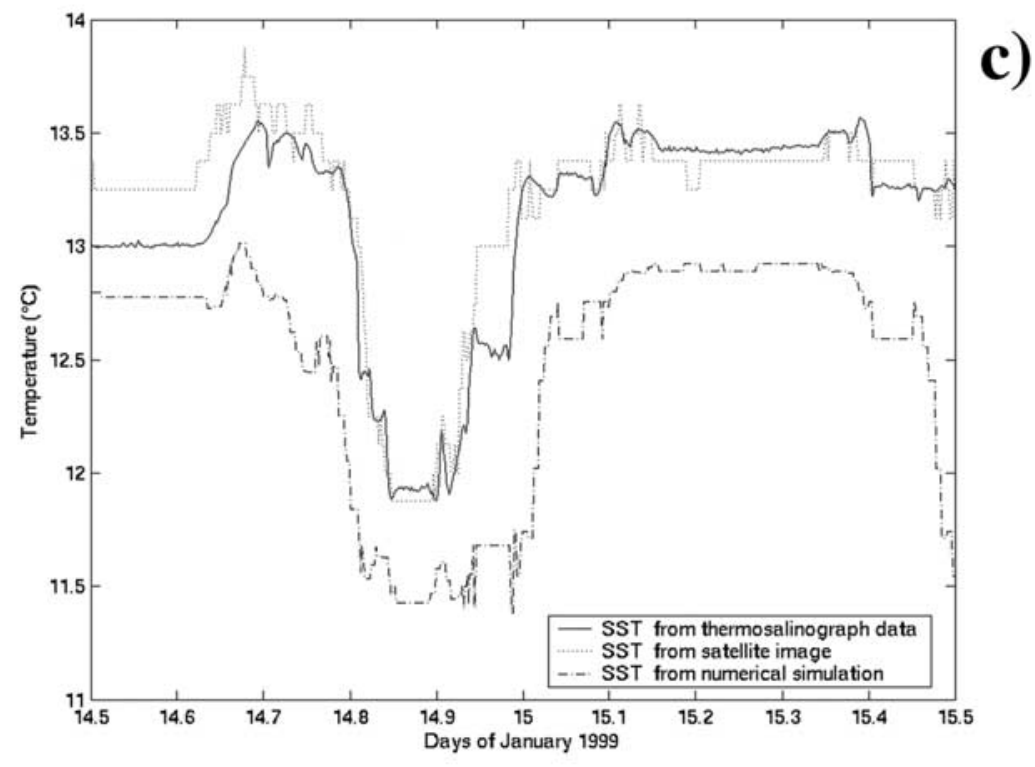

Figure 2c. Evolution of the surface temperature measured by the vessel (solid line), from the SST image (dotted line), and from the model (dashed line). 

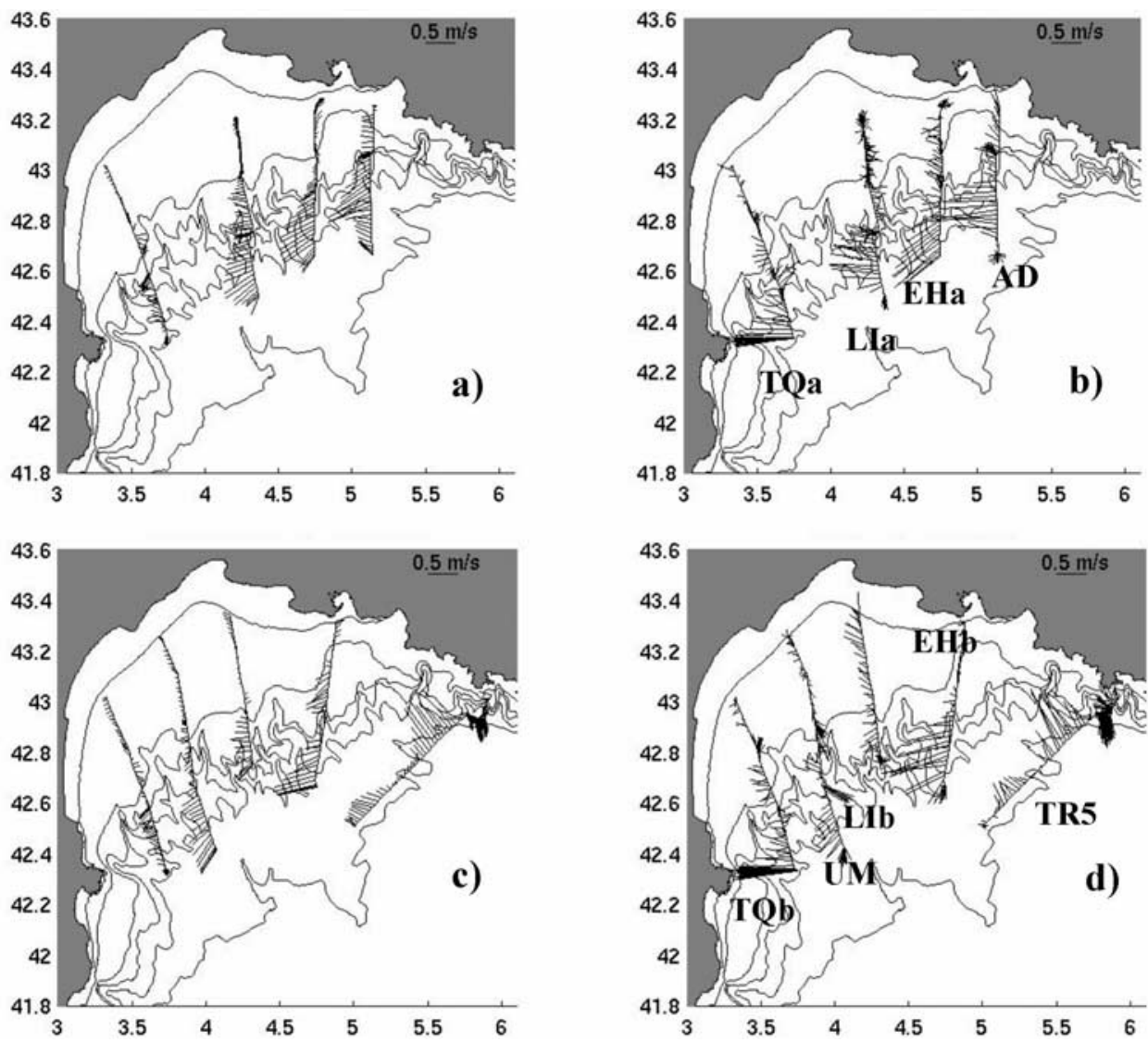

Figure 3. Stick-plot of horizontal currents along the main transects of MOOGLI3 at $32 \mathrm{~m}$ depth. (a) Modeled currents for the first period of the cruise (11-15 January 1999). (b) ADCP measured currents for the same period. (c) Modeled currents for the second period (15-21 January 1999). (d) ADCP measured currents for the same period. Transects are named from their two ending stations [Petrenko, 2003].

modeling approach is validated with a qualitative comparison of the modeling results to the observations.

\subsection{Horizontal Currents}

[16] The horizontal currents measured during the MOOGLI3 cruise are available all along the trajectory of the vessel from $16 \mathrm{~m}$ to $400 \mathrm{~m}$ deep. In order to validate the 3-D modeling of the circulation and its time and space variability, stick-plot and vertical sections will be shown and discussed in the next paragraphs. The comparison of observed currents and modeled ones will be made splitting the cruise in two periods.

\subsubsection{First Period: From 11 January to 15 January 1999}

[17] The main transects investigated during this period of the cruise and the horizontal currents measured at $32 \mathrm{~m}$ deep are plotted on Figure $3 \mathrm{~b}$. Weak currents are observed on the shelf by comparison with the MOOGLI1 cruise [Estournel et al., 2003]. Above the shelf break, along the continental slope, the NC is clearly detected and its core oscillates from northwestern to southwestern direction (transects AD, EH and LI, Figure 4b). In the modeled outputs, represented in Figure $3 \mathrm{a}$, the continental shelf is correctly characterized by weak currents. The various changes in direction observed on transect TQ are correctly reproduced. The modeled NC vein is well positioned along the shelf break despite a southeastward shifted location concerning the TQ transect. As regards the vertical structure of these horizontal currents, the observed position and dimension of the $\mathrm{NC}$ appear clearly on Figure 4b. As evidenced by Petrenko [2003], the vein is about $30 \mathrm{~km}$ wide and $250 \mathrm{~m}$ deep. It is not symmetrical vertically: Its southern limit is tilted northward with depth. Concerning the modeled NC (Figure 4a), it presents a very good agreement with the former description. Its width and depth are of the same order as the observed NC ones. The simulation reproduces its asymmetrical aspect, which is attributed to the surface circulation induced by the wind (different interpretation than the one of Petrenko [2003]). Indeed, a simulation without any wind stress (results not shown) does not show this feature. In fact, the circulation in the surface Ekman layer adds a new velocity component that shifts the NC core offshore.

\subsubsection{Second Period: From 15 January to 21 January 1999}

[18] During the second period of the cruise (Figures $3 \mathrm{c}$ and $3 \mathrm{~d}$ ), observed and modeled currents over the continental shelf are once again weak and directed mainly westward. The NC position has not changed compared to the first period and is well reproduced by the model. This is confirmed by the vertical sections of the transects (Figure 5). At the entrance of 
a)
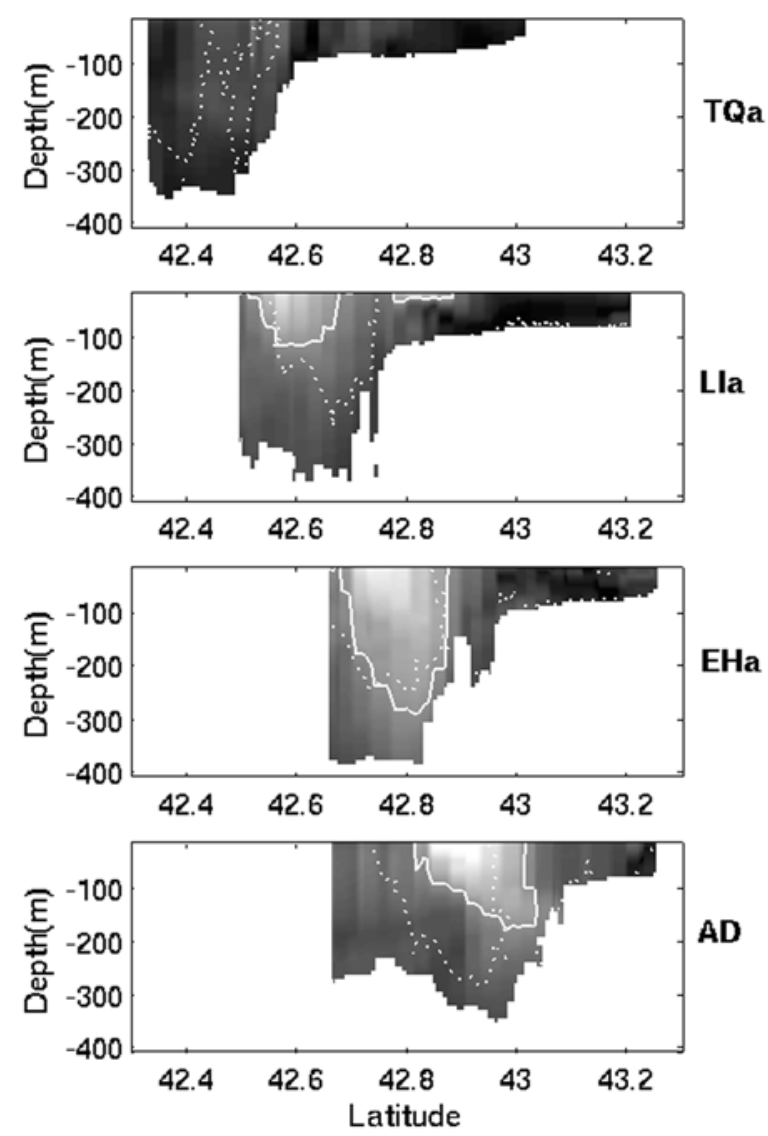

b)

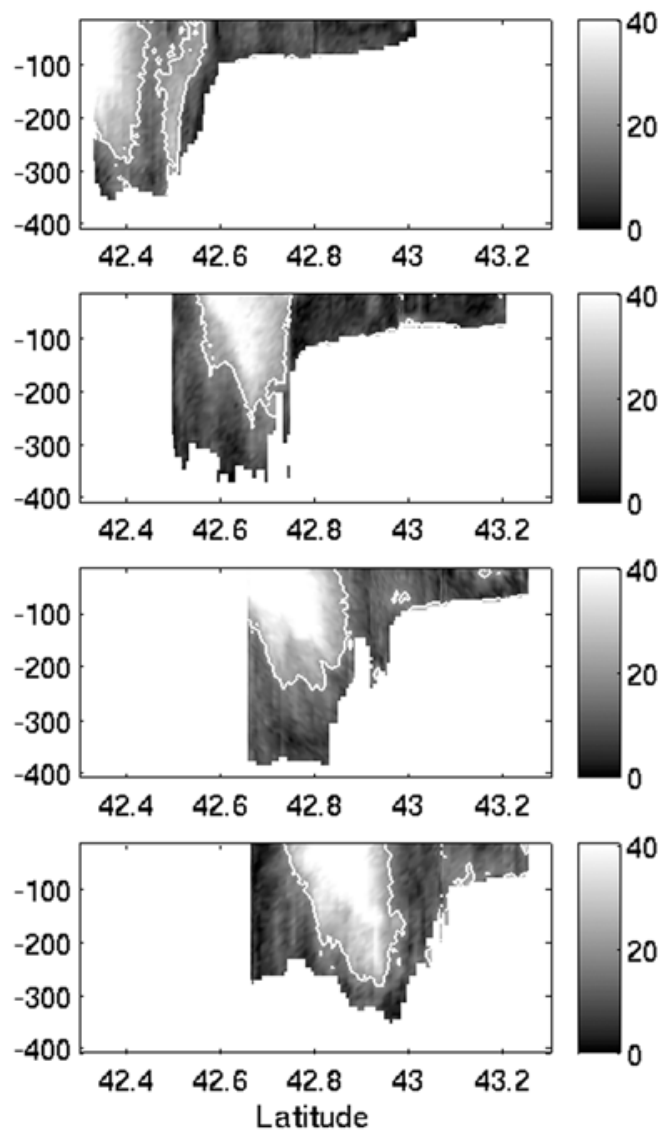

Figure 4. Vertical sections of current amplitude along the main transects made during the first lag of the MOOGLI3 experiment. (a) Simulation. (b) Observation. The white line corresponds to the $20 \mathrm{~cm} / \mathrm{s}$ isotach. The white dotted line on Figure 4a corresponds to the $20 \mathrm{~cm} / \mathrm{s}$ isotach of the observed currents (Figure 4b).

the gulf, the last transect of the cruise (TR5, Figures $3 \mathrm{c}$ and $3 d)$ shows two veins of westward current, both in measurements and modeled outputs. This feature does not constitute, as was hypothesized by Petrenko [2003], a splitting of the initial NC core (coming from the Ligurian Sea) into two branches. It corresponds in fact to the reinforcement of the $\mathrm{NC}$ core by a cyclonic circulation, which flows around the convection area. Indeed, the vertical section of this transect (Figure 5) highlights both in observations and modeling that the two veins have vertical different shapes and vertical extension. Hence they do not refer to the same process. Moreover, a modeled output of the 32-m-depth currents (Figure 6) shows clearly the two different veins. At the eastern part of the transect TR5, the observed countercurrent, located between the NC core and the coast, is well reproduced in the simulation (Figure 5). Modeling tests show that the wind structure constitutes the main forcing of this circulation instead of the bottom topography as one could have thought at first. Indeed, this countercurrent does not appear in a simulation without the wind-forcing.

\subsection{Horizontal Distribution of Surface Temperature and Salinity}

[19] The thermosalinometer measurements collected during the cruise enable the validation of modeled sea surface temperature and salinity. As shown in Figure 7, modeled salinity and temperature are less important than the observed ones: about $-0.3 \%$ for the salinity and $-0.5^{\circ} \mathrm{C}$ for the temperature. The haline difference would be linked to the initial state. In fact, a simulation with higher values of salinity at $t=t_{0}$ shows a good comparison with MOOGLI3 data. The thermal difference would come from an overestimation of heat fluxes in the simulation. Starting with warmer initial state leads indeed to a good comparison with the MOOGLI3 data. Despite these results, the initial simulation is kept to ensure not too warm conditions at open boundaries. Nevertheless, the horizontal gradients are very well reproduced: The position of the Rhône river plume is in accordance with the observations and the differences in temperature and salinity between the continental waters, the NC flow, and the offshore water are similar in modeling and measurements.

[20] As previously shown in section 2, the AVHRR SST images constitute a real potential to validate the modeled fields of SST and their temporal evolution. The comparison of the model output for the 15 January at 0000 hours with the corresponding AVHRR data (Figures $2 \mathrm{a}-2 \mathrm{c}$ ) gives a similar conclusion to the comparison with thermosalinograph: The modeled horizontal gradients are in very nice agreement with the satellite ones. However, modeled tem- 
a)
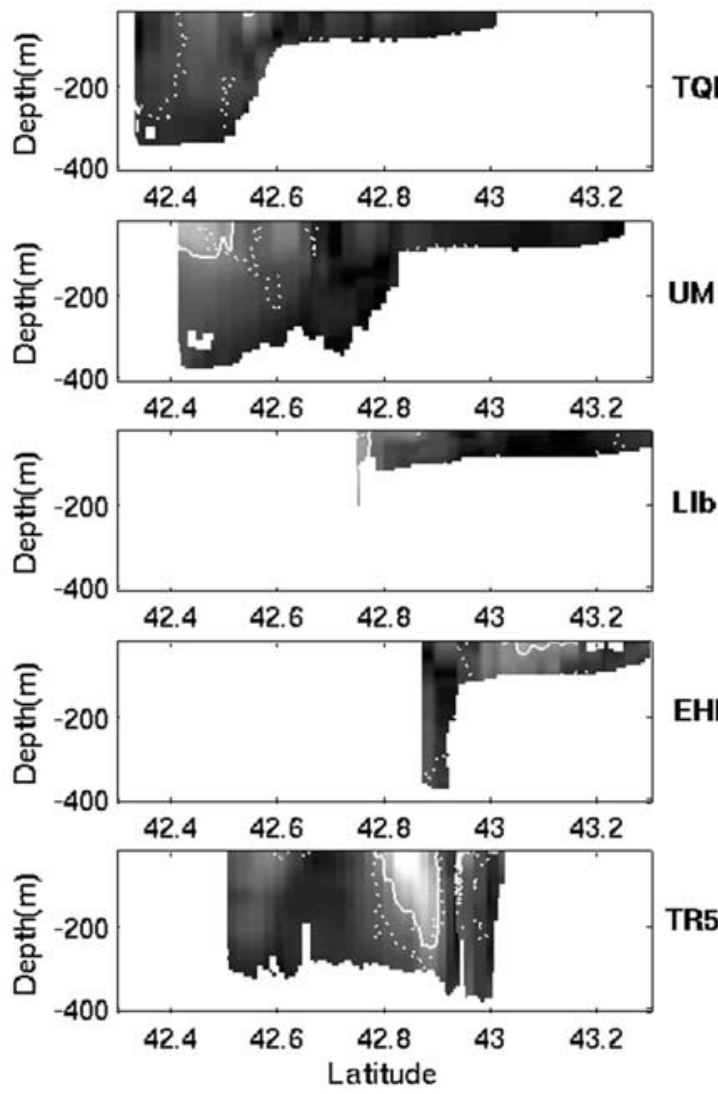

b)
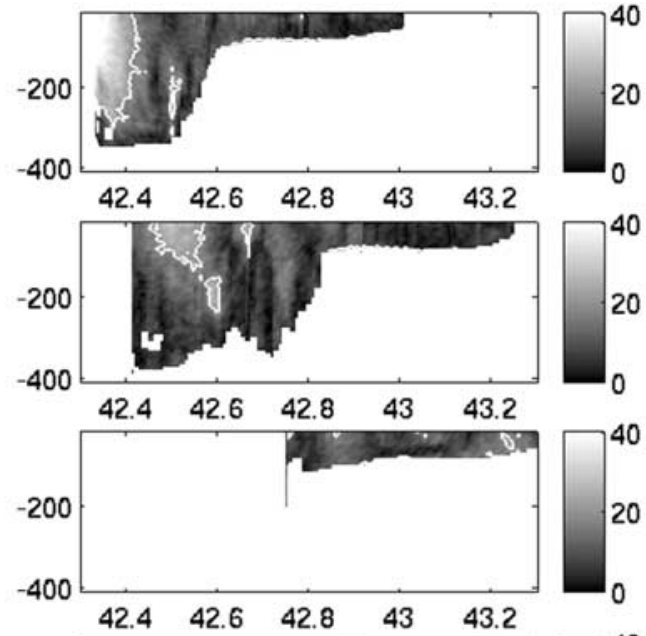

EHb

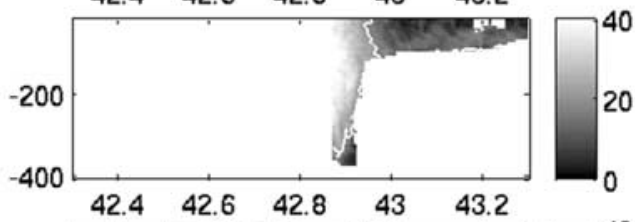

TR5

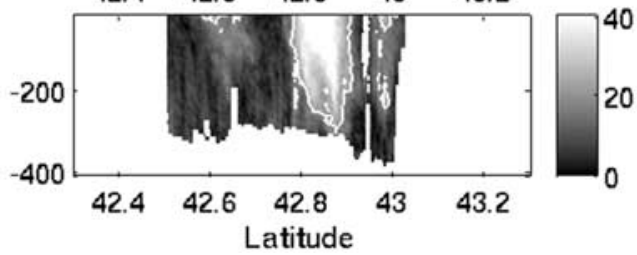

Figure 5. Vertical sections of currents amplitude along the main transects made during the second lag of the MOOGLI 3 experiment. (a) Simulation. (b) Observation. The white line corresponds to the $20 \mathrm{~cm} / \mathrm{s}$ isotach. The white dotted line on Figure 5a corresponds to the $20 \mathrm{~cm} / \mathrm{s}$ isotach of the observed currents (Figure 5b).

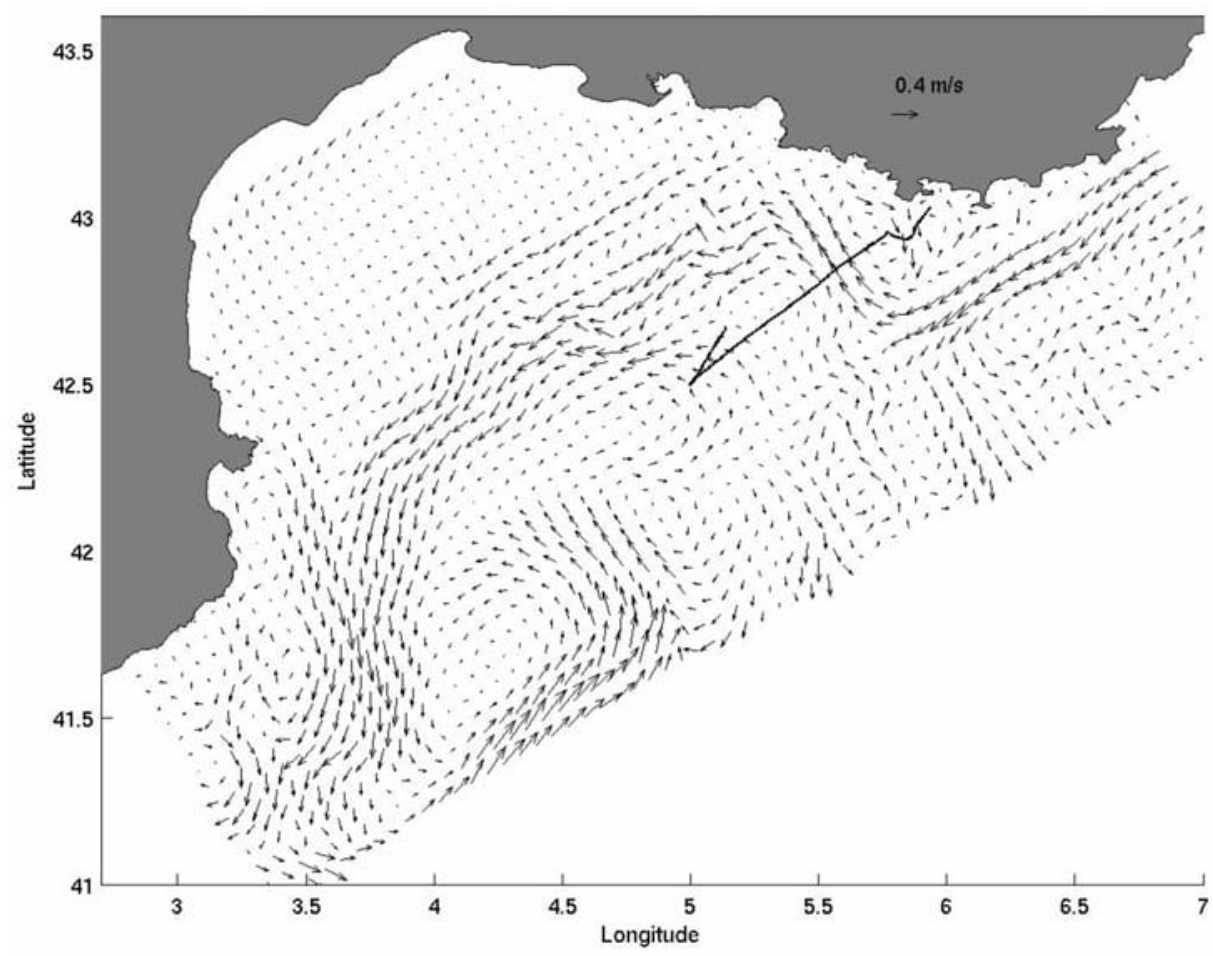

Figure 6. Modeled circulation at $32 \mathrm{~m}$ depth on 20 January 1999 at 0000 hours. 

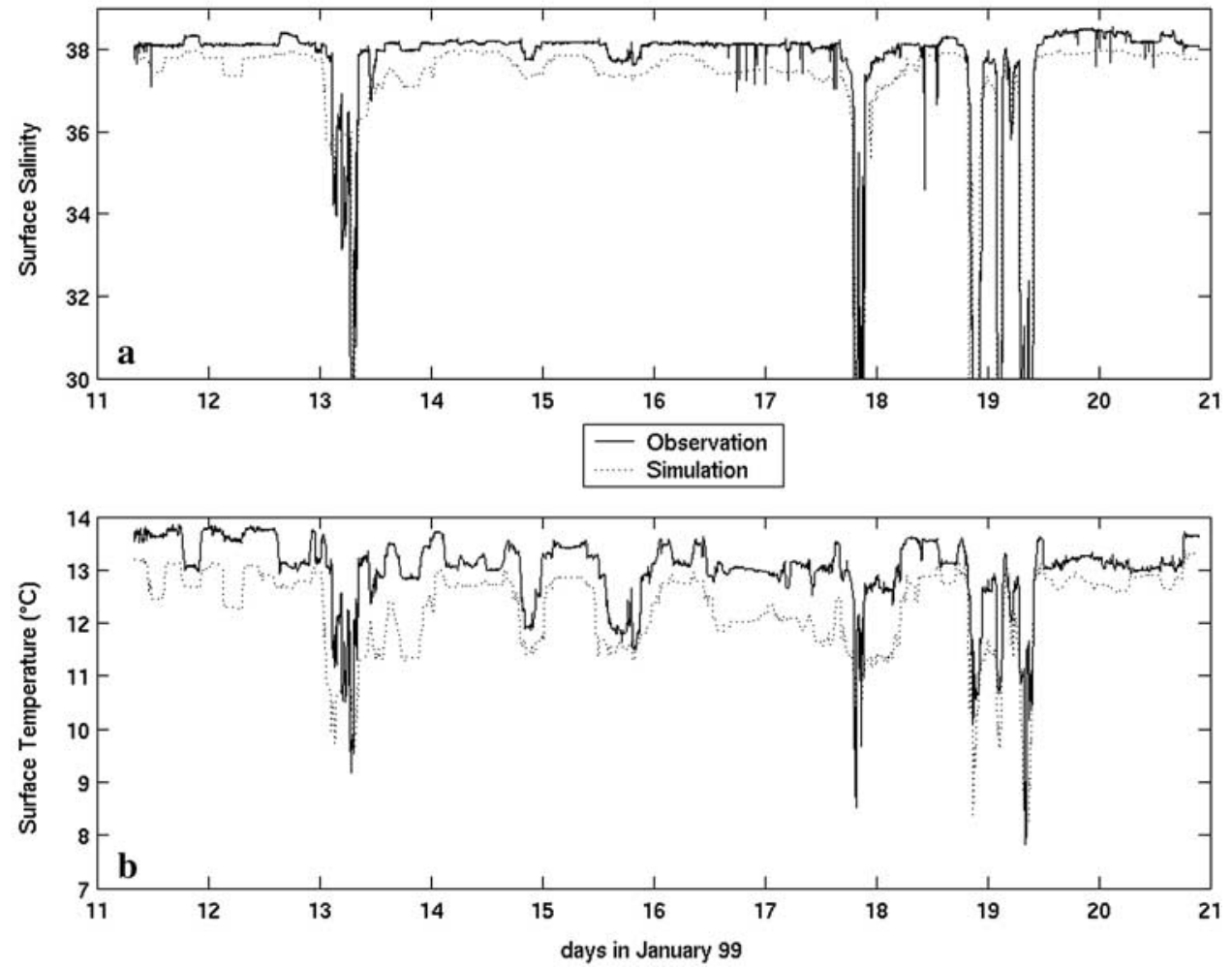

Figure 7. Temporal variation of the measured (solid line) and modeled (dashed line) sea surface (a) salinity and (b) temperature along the track of the vessel.

perature is about $0.5^{\circ} \mathrm{C}$ inferior to the AVHRR data (Figure 2c). Then, considering only the anomaly of temperature fields (the mean of the field is removed from each value), one can obtain a correct validation of the modeled
SST (Figure 8). For the three different dates, modeled positions of thermal fronts agree with the observed ones, mainly in the southwestern continental shelf. Despite some differences in the pattern, the interaction between the Rhône
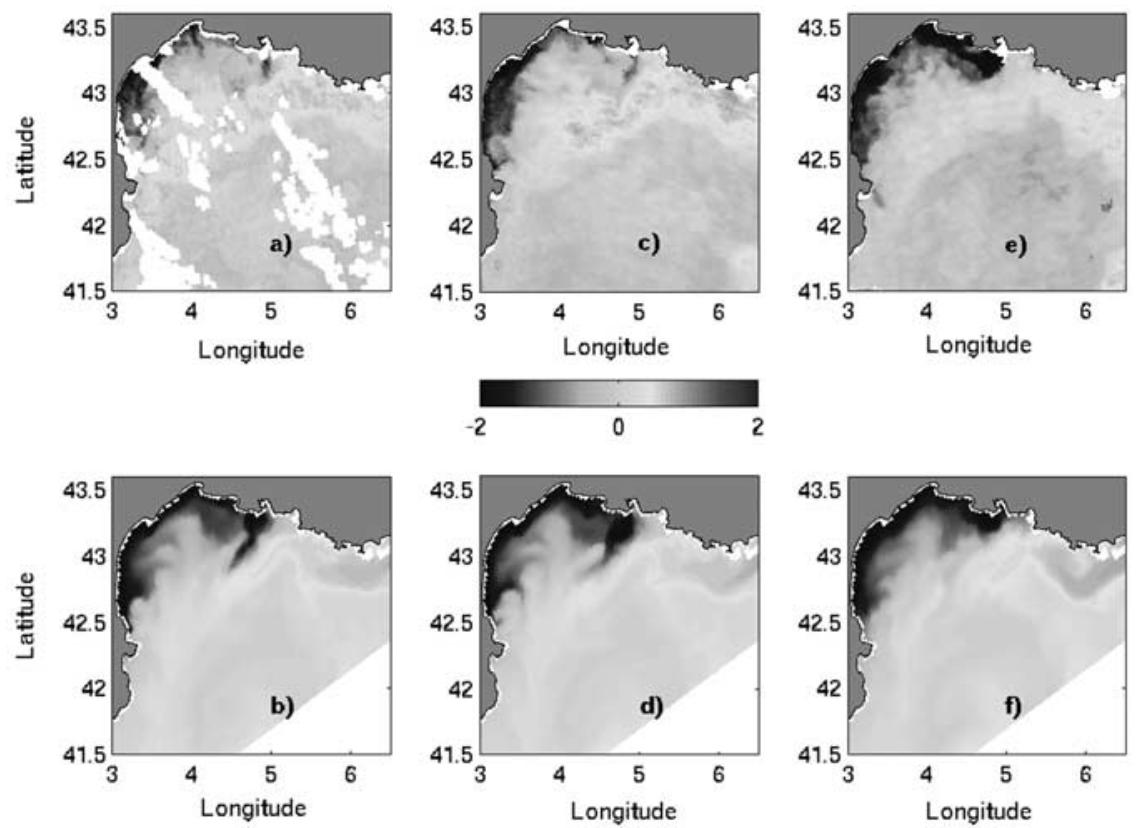

Figure 8. Maps of the sea surface temperature anomaly (the mean temperature signal of each map has been removed): (a, b) 13 January 1999 at 0000 hours, (c, d) 15 January 1999 at 0000 hours, and (e, f) 19 January 1999 at 0000 hours. Figures 8a, 8c, and 8e are AVHRR images; Figures 8b, 8d, and 8f are modeled outputs. See color version of this figure at back of this issue. 

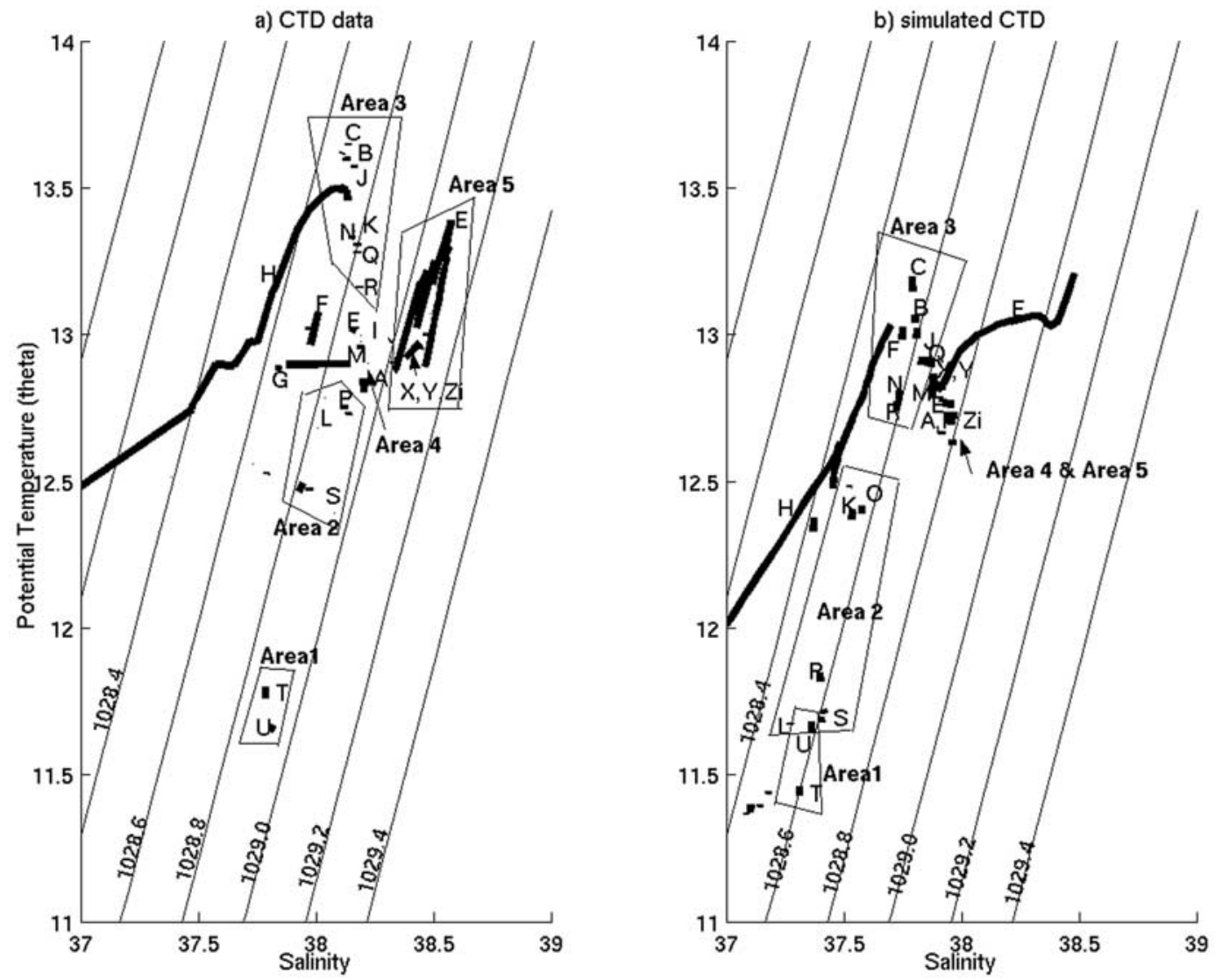

Figure 9. (a) Theta-S diagrams for the whole CTD data and (b) the corresponding modeled results. The letters refer to the CTD stations (Figure 1).

river plume and the $\mathrm{NC}$ is well reproduced. Moreover, the temporal aspect of the SST fields is also nicely modeled in the simulation.

\subsection{Vertical Distribution of Temperature and Salinity}

[21] During the cruise, 48 CTD profiles were made at 30 pre-chosen locations in the GoL (Figure 1). They show the vertical hydrology structure of the GoL, and go as deep as $1500 \mathrm{~m}$ for the offshore stations. A theta-S diagram for the whole set of CTD data (Figure 9a) permits us to classify the stations in five areas (Figure 1). The coastal shelf (region 1) is filled with the coldest and freshest waters $\left(11.7^{\circ} \mathrm{C}-37.8\right)$ of the GoL. The middle shelf water (region 2 ) is about $0.8^{\circ} \mathrm{C}$ warmer and 0.25 saltier than the one of the former area. Its $80-\mathrm{m}$ profiles are all almost homogeneous (pinpoint representation on theta-S diagrams). The shelf break (region 3) constitutes the warmest area of the GoL and its salinity is little higher than above the middle shelf. The open ocean (region 5) deals with the denser water mass of the GoL. Most of the CTD stations of this area show homogeneous profiles of Western Mediterranean Deep Water (WMDW) $\left(12.8^{\circ} \mathrm{C}-38.4\right)$. Nevertheless, at station $\mathrm{E}$, one can notice the typical three-layered stratification [Mertens and Schott, 1998]: The top $150 \mathrm{~m}$ is occupied by Atlantic Water $\left(12.8^{\circ} \mathrm{C}-38.1\right)$, which overlies the warmer and saltier Levantine Intermediate Water $\left(13.4^{\circ} \mathrm{C}-38.5\right)$ extending from 150 to $500 \mathrm{~m}$. Deeper than
$500 \mathrm{~m}$, one finds a transition zone with the very homogeneous WMDW that lies below $1500 \mathrm{~m}$. The open slope (region 4) constitutes a transition area between the three latter areas previously described.

[22] Despite being colder than the observations, the modeled temperature (Figure 9b) shows approximately the same features. The coldest and freshest area corresponds to the coastal ocean and the gradient toward Open Ocean is well reproduced. Thus the middle shelf (region 2) is little warmer than region 1 . The open slope (region 4) and the open ocean (region 5) are not easily distinguishable on the simulated theta-S diagram. They both exhibit the WMDW characteristics $\left(13^{\circ} \mathrm{C}-38.4\right)$, but with a more stratified situation than in the CTD data.

\subsection{Temperature Evolution Near the Lacaze-Duthiers Canyon}

[23] The mid-depth and bottom measurements made in this canyon by Béthoux et al. [2002] are compared, respectively, to the modeled temperature at $300 \mathrm{~m}$ and $570 \mathrm{~m}$ depth (Figures 10a and 10b, respectively). The model reproduces correctly the water-cooling of mid-February but with a smoother shape.

[24] The winter hydrology of the GoL is then well modeled by the ocean model. This feature, associated with a good reproduction of the 3-D dynamics as seen in previous sections, permits us to use confidently the simulation as a numerical tool to understand the winter processes 

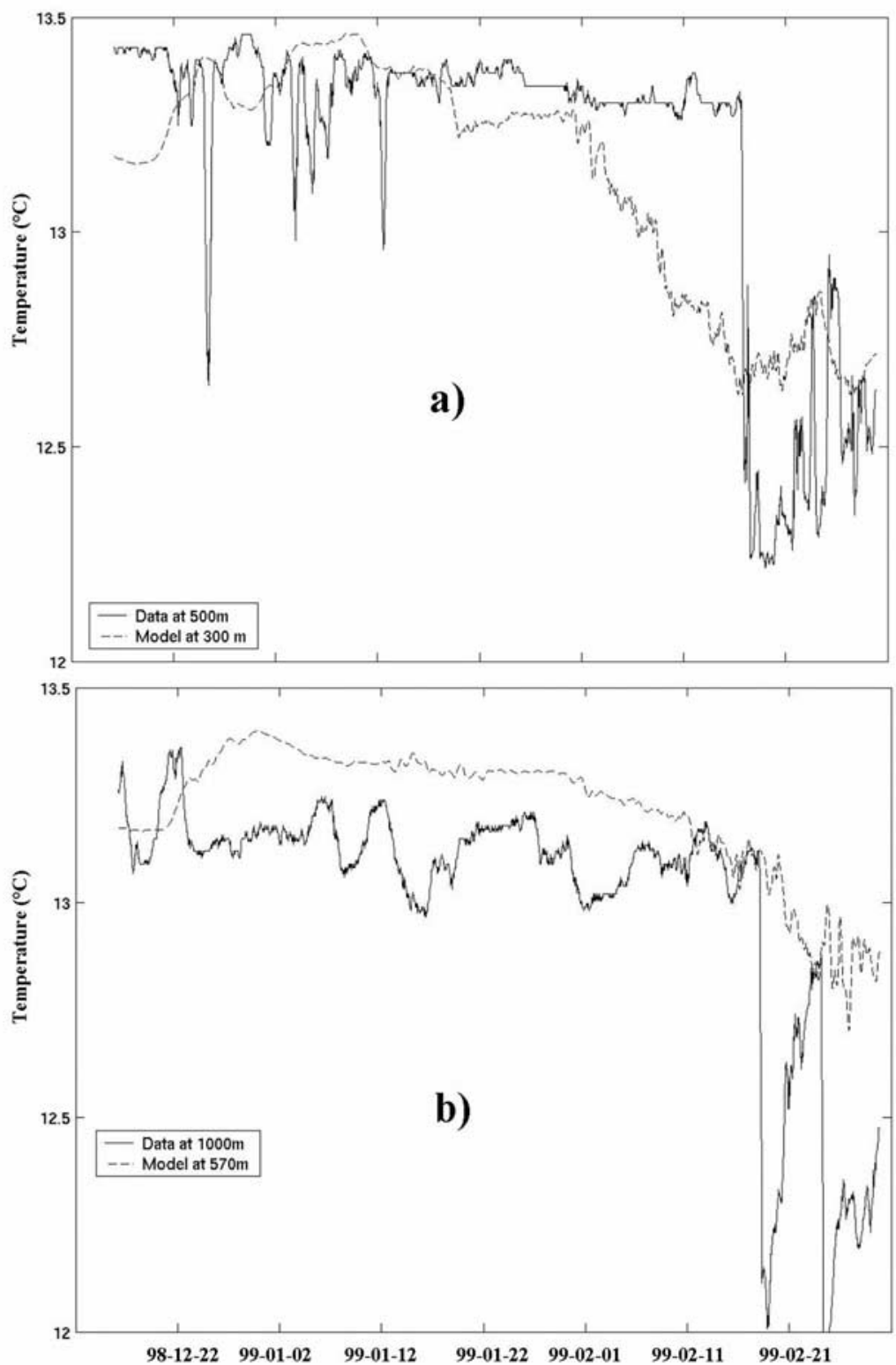

Figure 10. Temperature observations at $500 \mathrm{~m}$ and $1000 \mathrm{~m}$ depths in the Lacaze-Duthiers canyon during winter 1999 and modeling results at the same location.

Table 1. Climate Data Extracted From Person [1974] and Bethoux et al. [2002], and Meteo-France Data Measured at Cap Bear for the MOOGLI3 Modeling Period

\begin{tabular}{|c|c|c|c|c|}
\hline & Mean $(1950-1959)$ & $1968-1969$ & $1970-1971$ & $1998-1999$ \\
\hline \multicolumn{5}{|c|}{ December } \\
\hline Wind $>5 \mathrm{~m} / \mathrm{s}$, days & 20.3 & 28 & 27 & 13.2 \\
\hline Wind $>16 \mathrm{~m} / \mathrm{s}$, days & 12.9 & 12 & 14 & 5.5 \\
\hline Monthly mean temperature, ${ }^{\circ} \mathrm{C}$ & 9.1 & 10.6 & 7.2 & 10 \\
\hline \multicolumn{5}{|c|}{ January } \\
\hline Wind $>5 \mathrm{~m} / \mathrm{s}$, days & 21.8 & 19 & 22 & 14.2 \\
\hline Wind $>16 \mathrm{~m} / \mathrm{s}$, days & 13.4 & 11 & 16 & 6.2 \\
\hline Monthly mean temperature, ${ }^{\circ} \mathrm{C}$ & 8.7 & 10.2 & 8.9 & 10.2 \\
\hline \multicolumn{5}{|c|}{ February } \\
\hline Wind $>5 \mathrm{~m} / \mathrm{s}$, days & 19.8 & 23 & 25 & - \\
\hline Wind $>16 \mathrm{~m} / \mathrm{s}$, days & 13.6 & 15 & 23 & 20 \\
\hline Monthly mean temperature, ${ }^{\circ} \mathrm{C}$ & 10.2 & 7.6 & 9.4 & - \\
\hline
\end{tabular}




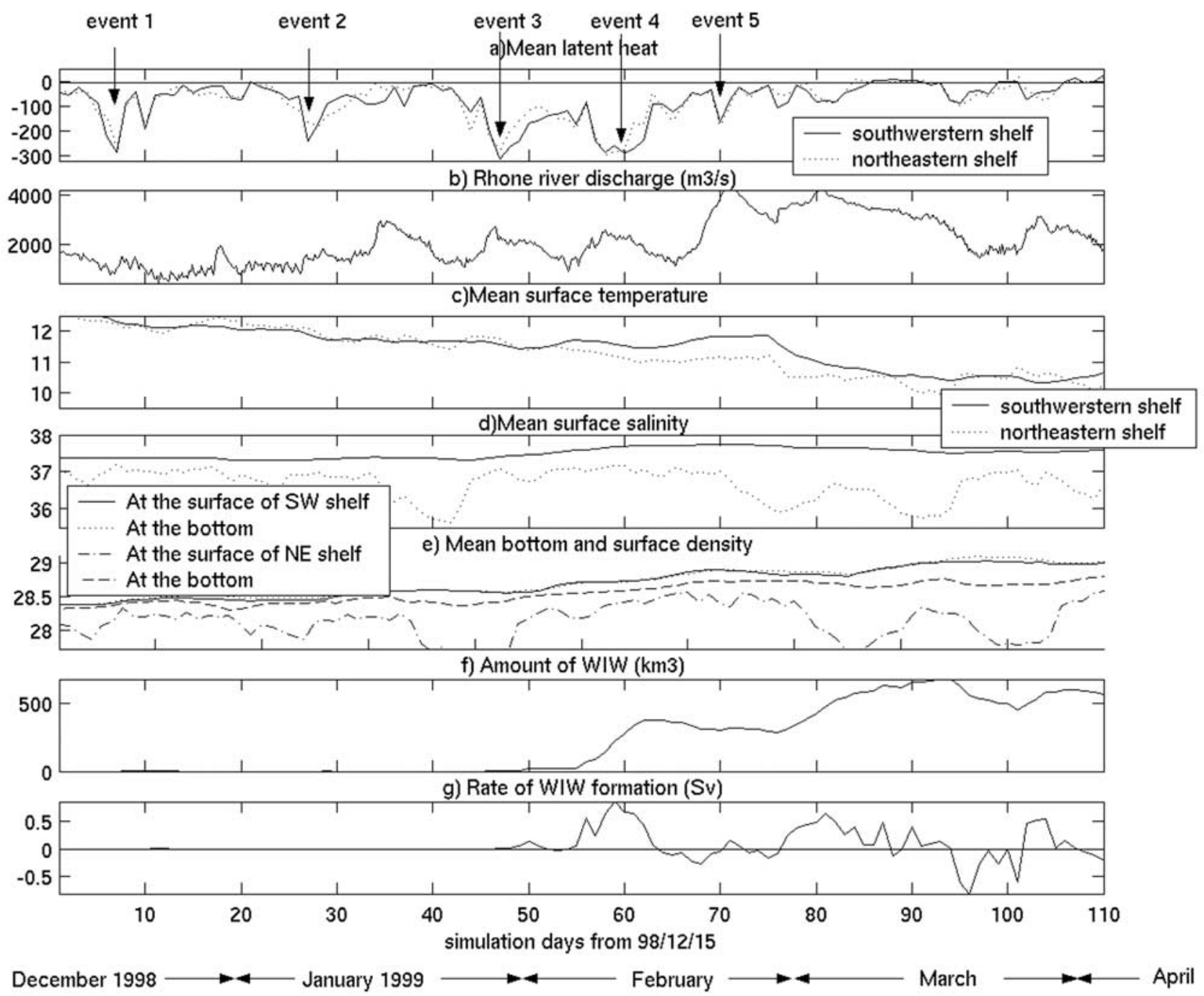

Figure 11. Time evolution of (a) the mean latent heat fluxes, (b) the Rhône river discharge, (c) the mean surface modeled temperature, (d) the mean surface modeled salinity, (e) the mean surface and bottom modeled density, (f) the amount of WIW formed in the simulation, and (g) the rate of WIW formation in the simulation from 15 December 1998 and 4 April 1999.

of the GoL such as the dense water formation (WIW) over the GoL's continental shelf.

\section{WIW Formation in the GoL During the 1999 Wintertime}

[25] The formation of dense water over a continental shelf constitutes a widespread coastal ocean process. Sixty-one locations are nowadays listed [Ivanov et al., 2004] all over the world. If this phenomenon occurs mainly in the Antarctic and Artic areas (Norwegian, Greenland, Labrador, and Weddel Seas), it is also observed at midlatitude. Nevertheless, these authors have omitted the northwestern part of the Mediterranean Sea (particularly the GoL) as a location of formation of dense water over a continental shelf. The MEDOC Group [1970] made the first observation of such formation over the GoL during winters 1969 and 1971. Fieux [1974] described a dense plume reaching $\sigma_{t}$ values of 29.07 on the southwestern part of the shelf.
Person [1974] observed WIW spread over the whole shelf during the 1971 winter. He studied the Cap Bear's atmospheric conditions for this winter in comparison with the previous winters conditions and demonstrated that severe conditions (strong winds, intense negative heat fluxes) are needed for WIW formation. Studying the 1970-1971 wintertime, he showed that dense water over the continental shelf first appeared in January and then extended to the whole shelf in March. Using Cap Bear's observations, he performed the average of atmospheric temperatures, calculated the number of days for which wind velocities were strong (above over 5 and $16 \mathrm{~m} \mathrm{~s}^{-1}$ ), and estimated the evaporation for each month of winter 1970-1971. He compared these values with those of the 1968-1969 winter and with the 1950-1959 average. These results are related in Table 1. It clearly appears that the 1970-1971 winter presented very strong winds, especially in February and March and in cold weather (in December and March). Moreover, high values of evaporation were observed at 

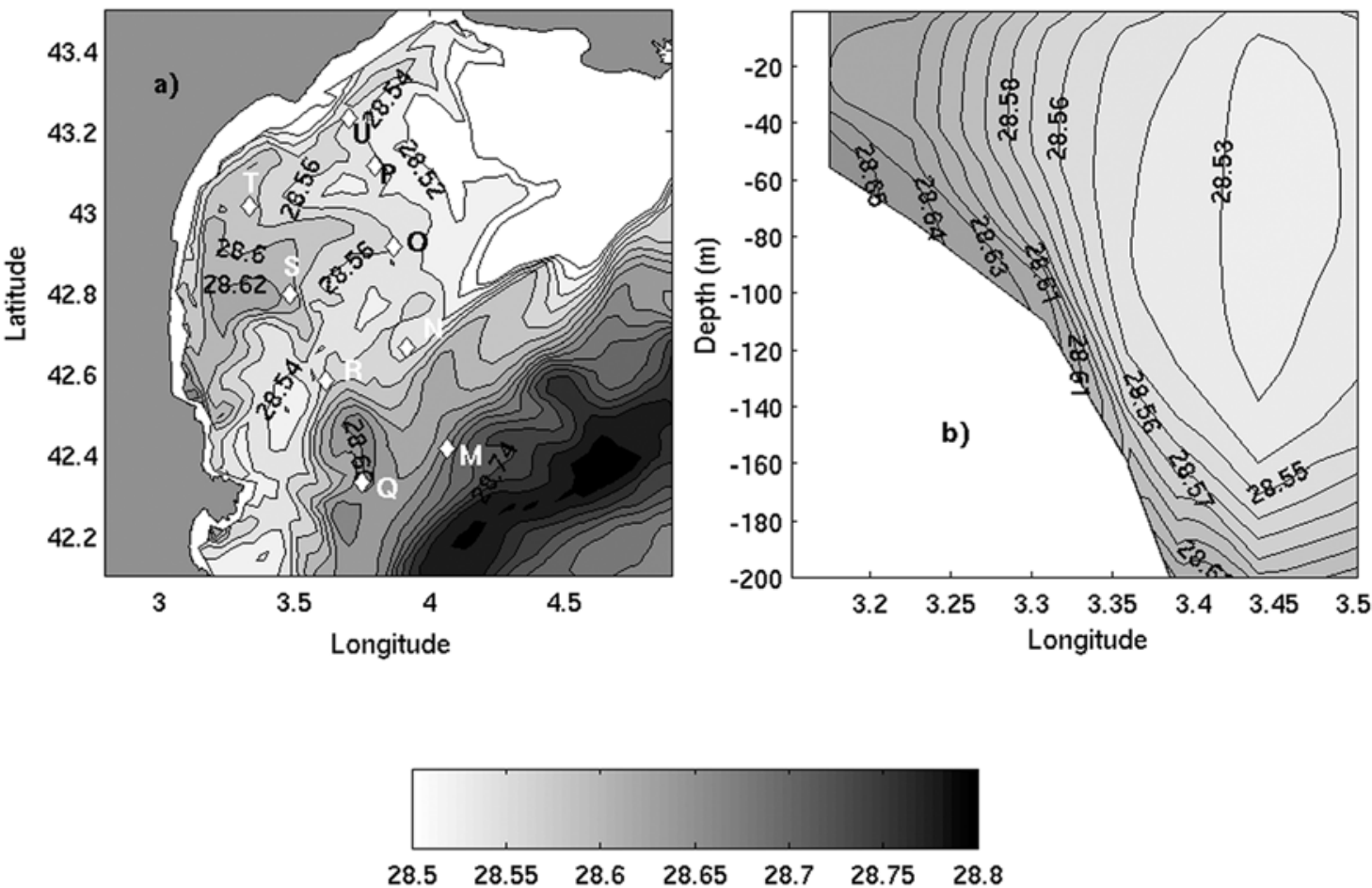

Figure 12. (a) Horizontal contours of $\sigma_{t}$ at $20 \mathrm{~m}$ depth on 15 January 1999 in the western shelf of the GoL. The CTD locations are indicated with diamonds. (b) Vertical section of $\sigma_{\mathrm{t}}$ along the $42.53^{\circ} \mathrm{N}$ parallel at the same time.

the same time (not shown here). Person [1974] concluded that the cold atmospheric events, associated with a strong evaporation, of December and the beginning of January induced the formation of cold and then dense water on the shelf. This event started in January, while they usually start in February, when they happen. This production of WIW continued in February and got even stronger in March.

[26] During the 1998-1999 wintertime, a rather calm period extends from 8 December 1998 to 26 January 1999 [Béthoux et al., 2002]. During the 15 December 1998 to 4 April 1999 period, the temporal evolution of the mean latent heat flux above two parts of the GoL's continental shelf (Figure 11a) exhibits five major atmospheric events. From January 26 to February 23, the wind speed has always been stronger than $16 \mathrm{~m} / \mathrm{s}$ and was stronger than $25 \mathrm{~m} / \mathrm{s}$ during 13 days. The permanent strong negative heat fluxes induce a regular cooling of the simulated shelf surface water (Figure 11c), as well as a weak increase of the simulated shelf surface salinity (Figure 11d). Thus, in the simulation, the density (Figure 11e) increases above the whole shelf with stair-like patterns, which are correlated with the peaks of latent heat fluxes. The MOOGLI3 experiment takes place after the second event. During this cruise, only one CTD station, station S (Figure 1), had dense $\left(\sigma_{t}=28.9\right)$ homogeneous waters throughout the water column. No other stations over the shelf showed waters with $\sigma_{\mathrm{t}}$ higher than at $\mathrm{S}$. Reduced density is calculated to compare the station $\mathrm{S}$ to its nearest neighbors: $0.06 \mathrm{~kg} / \mathrm{m}^{3}$ for station $\mathrm{R}, 0.10 \mathrm{~kg} / \mathrm{m}^{3}$ for station $\mathrm{T}$, and $0.03 \mathrm{~kg} / \mathrm{m}^{3}$ for station O. Despite a $\sigma_{\mathrm{t}}$ value inferior to 29 , the water mass observed at $\mathrm{S}$ constitutes a relatively dense water plume compared with ambient shelf waters. The offshore stations show water mass denser than the dense plume of the shelf. Therefore a possibility for this dense shelf water is to flow above the shelf and down the slope until it reaches its neutral level (zero reduced gravity) near offshore locations. The results of the simulation for 15 January (Figure 12a) agree quite well with this description of dense water in the GoL. Indeed, the modeled dense water area is located closer to station $\mathrm{S}$ than to the other shelf stations. Despite the eastward shape of the plume, a vertical section of the modeled density along the $42.8^{\circ}$ parallel (not shown) does not exhibit a propagation on the bottom in this direction. The dense water formation is still in progress (Figure 11e), but WIW has not yet appeared (Figures $11 \mathrm{f}$ and $11 \mathrm{~g}$ ). The weak slope and relatively low density do not permit to clearly generate a dense plume over the bottom. Nevertheless, one can already find a dense bottom blob located at $42.5^{\circ} \mathrm{N}$ in the western part of the shelf (Figure 12a). No in situ data are available there to validate this model result.

[27] During late winter (i.e., in February and March), the density increases above the shelf. This WIW formation appears clearly in the modeled Theta-S diagrams (Figures $13 \mathrm{c}$ and 13d). The temporal evolution of WIW formation (Figure 11f) shows that the quantity of WIW increases after the third atmospheric event. The maximum rate $(0.85 \mathrm{~Sv})$ of WIW's formation is reached during the fourth atmospheric event (Figure $11 \mathrm{~g}$ ). The quantity of WIW reaches its maximum (about $680 \mathrm{~km}^{3}$ ) after mid-March. The weak atmospheric conditions that happen then lead to a diminution of WIW over the shelf until the beginning of 

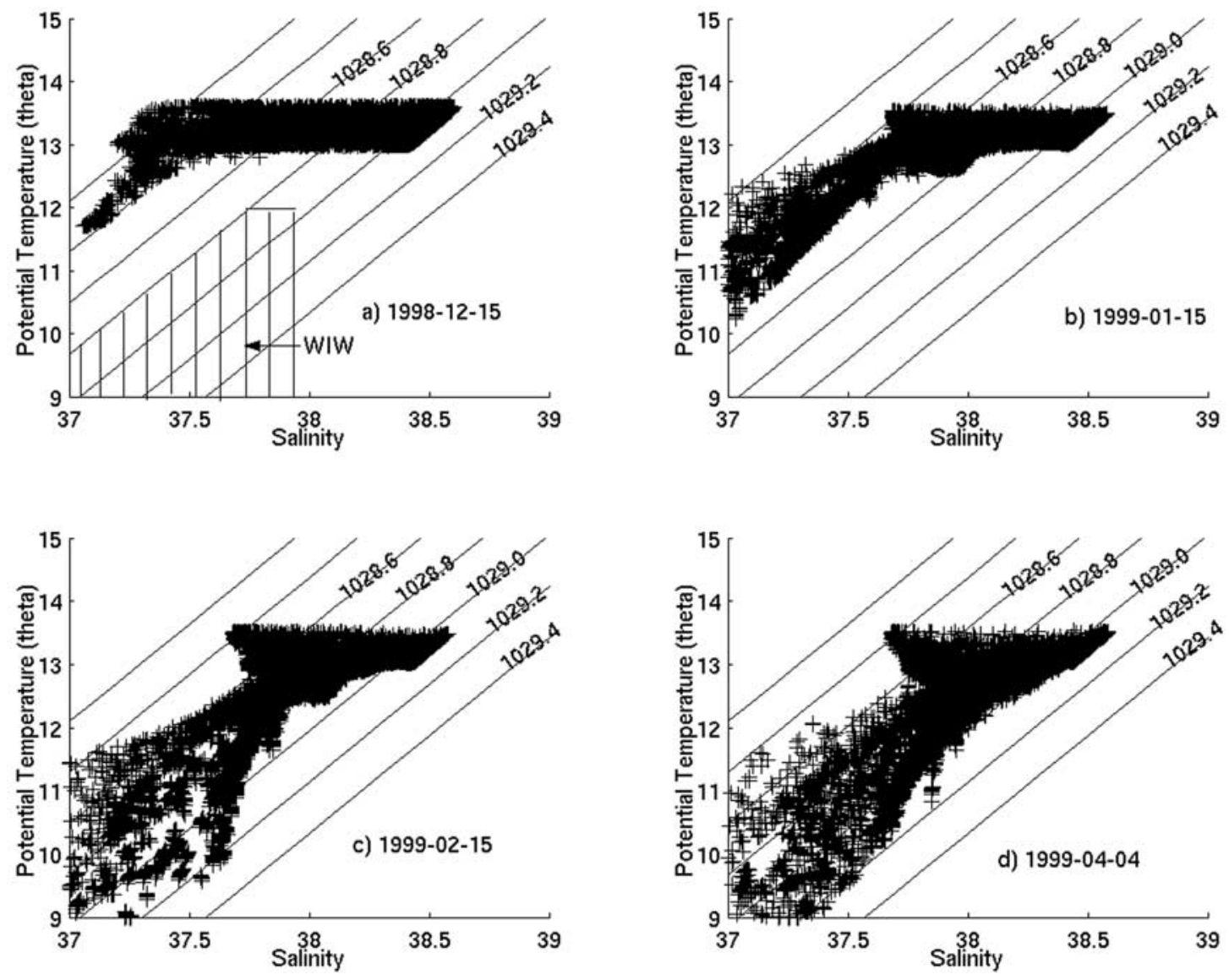

Figure 13. Modeled theta-S diagrams. (a) Initial state: 15 December 1998, (b) 15 January 1999, (c) 15 February 1999, and (d) 4 April 1999.

April. After a last short increase, the WIW quantity reaches $570 \mathrm{~km}^{3}$ at the end of the simulation. However, one can wonder about the precision of this numerical estimation of the amount of WIW formed and of its rate of formation during the wintertime 1998-1999. In fact, this estimation is made every simulated day by adding the elementary volumes of each 3-D grid point which fulfils the following conditions: $T<12^{\circ} \mathrm{C}, S<37.9, \rho>28.8$, and depth $>400 \mathrm{~m}$. This criterion takes into account both the well-known characteristics of the shelf waters and their descent on the slope until $400 \mathrm{~m}$. However, small modifications in this criterion result in different amounts of WIW formed during the simulated winter. In order to examine the precision of the proposed estimation, some sensibility tests have been run, and their results are summarized in Table 2. These estimations appear to be particularly sensitive to the haline definition of WIW. The influence of the offset in temperature and salinity (compared with MOOGLI3 observations; see section 3.2) is also examined thanks to a new simulation. In the latter, the initial state is set warmer and saltier than case 1 to 4 simulations, thanks to the addition of spatial uniform vertical profiles. This simulation leads to a smaller amount (up to $390 \mathrm{~km}^{3}$ ) of WIW formed (see Table 2, case 5), but this value remains in the error interval of the estimation. Finally, $500 \mathrm{~km}^{3}( \pm 25 \%)$ can be considered as a rough but reasonable amount of WIW formed in the GoL during wintertime 1998 1999.
[28] Once formed, the WIW moves on the bottom of the shelf. Thanks to modeling, one can detect several WIW's plumes flowing toward higher depths during the 19981999 wintertime. At the beginning of April, the simulation shows half a dozen WIW plumes, about $10 \mathrm{~km}$ wide each, extending on the shelf (Figure 14). The southwestern part of the shelf appears as the most favorable place for WIW formation. Indeed, the northeastern part is under the influence of the Rhône fresh water that tends to inhibit the dense water formation, particularly during the flood events of March (Figures 11 and 14). The westward circulation of the fresh plume and the along-slope $\mathrm{NC}$ current prevent the down-slope exportation of dense water cells in the eastern part of the Gulf. Thus, at the extreme southwest corner of the continental shelf, the neighborhood of Cap Creus appears as a narrow pathway for the coastal southwestward circulation. Analysis of simulation outputs shows that crossslope bottom currents are locally intensified thanks to a Venturi effect, enhancing downslope exportation of shelf waters (see section 5).

\section{Dynamics of WIW Spreading and Cascading Over the Shelf}

[29] In order to understand the displacement of WIW formed over the shelf, we have used some analytical parameters coming from a theoretical model. This model 
describes the dense water spreading only with the gravity forces and the bottom Ekman drainage. Thus the discrepancy in the plume propagation rate between the 3-D model and the theoretical one permits us to highlight and estimate the role of local processes in the strengthening of the WIW exportation.

\subsection{Theoretical Mode}

[30] In the absence of bottom friction, geostrophy and potential vorticity conservation demand that a dense plume moves along-slope, parallel to the isobaths, with the shallow water on its right (in the Northern Hemisphere). Indeed, as shown by Nof [1983] with his volume-integrated equations model, a balance between the downslope component of the gravity force and the upslope Coriolis force occurs. The mean speed of the plume does not depend on the shape of the plume but only on the reduced gravity $\mathrm{g}^{\prime}$, on the Coriolis parameter $f$ and on the bottom slope $\tan \theta$ :

$$
\left\|\overrightarrow{\mathrm{u}}_{\mathrm{Nof}}\right\|=\frac{g^{\prime}}{f} \tan \theta
$$

[31] Thus the severe constraint of the geostrophic balance (hereinafter called "the geostrophic constraint") strongly inhibits the downslope motion of dense water. The bottom friction effect constitutes one means of breaking this constraint and then of allowing the cascading of dense water by gravity [Nof, 1983]. As shown in Figure 15b, the friction force opposes the translation of the plume along-slope. This opposing force causes a change in the direction of propagation because it can only be balanced by the weight of the plume. Then the plume translation shows a downhill component (Figure 15b).

[32] Dense water can also be driven downslope by other processes, which can occur even in the absence of dense water. The Ekman drainage process, induced in the bottom layer by an along-slope geostrophic current $\overrightarrow{\mathrm{u}}_{0}$, belongs to those processes (Figure 15a). Indeed, near the bottom, the geostrophic current slows down due to friction effects. The Coriolis force is then reduced, permitting a downslope component $\overrightarrow{\mathrm{v}}_{\mathrm{ED}}$ to appear [Pedlosky, 1987].

[33] Shapiro and Hill [1997], hereinafter SH97, study the propagation of a dense water plume on the bottom by considering both the cascading and the Ekman layer process. They use for this study a more complex model than Nof's [1983] one, but not yet a full 3-D primitive equations model. They describe the spreading/cascading of dense water on the slope by using the following advectiondiffusion equation for the thickness of the plume $h$ :

$$
\begin{aligned}
\frac{\partial \mathrm{h}}{\partial \mathrm{t}}+ & \left(\mathrm{F}_{1} \overrightarrow{\mathrm{u}}_{\mathrm{B}}^{\mathrm{s}}+\mathrm{F}_{2} \overrightarrow{\mathrm{u}}_{0}^{\mathrm{s}}+\mathrm{F}_{3} \overrightarrow{\mathrm{u}}_{\mathrm{B}}+\mathrm{F}_{4} \overrightarrow{\mathrm{u}}_{0}\right) \cdot \vec{\nabla}_{\mathrm{H}} \mathrm{h} \\
= & \mathrm{F}_{5} \mathrm{~h}_{\mathrm{E}} \overrightarrow{\mathrm{k}} \cdot\left(\vec{\nabla}_{\mathrm{H}} \times \overrightarrow{\mathrm{u}}_{0}\right)+\frac{\mathrm{g}^{\prime} \mathrm{h}_{\mathrm{E}}}{\mathrm{f}} \vec{\nabla}_{\mathrm{H}} \cdot\left(\mathrm{F}_{6} \vec{\nabla}_{\mathrm{H}} \mathrm{h}\right) \\
& +\mathrm{F}_{6} \frac{\mathrm{g}^{\prime} \mathrm{h}_{\mathrm{E}}}{\mathrm{f}} \vec{\nabla}_{\mathrm{H}}^{2} \mathrm{~b}+\mathrm{w}_{\mathrm{ent}}
\end{aligned}
$$

where $w_{\text {ent }}$ represents the entrainment velocity from the upper layer (Figure 16b), $h_{E}$ is the Ekman depth $h_{\mathrm{E}}=\sqrt{\frac{2 \mathrm{~K}}{\mathrm{f}}}$ with $K$ as the vertical diffusivity and $f$ as the Coriolis 

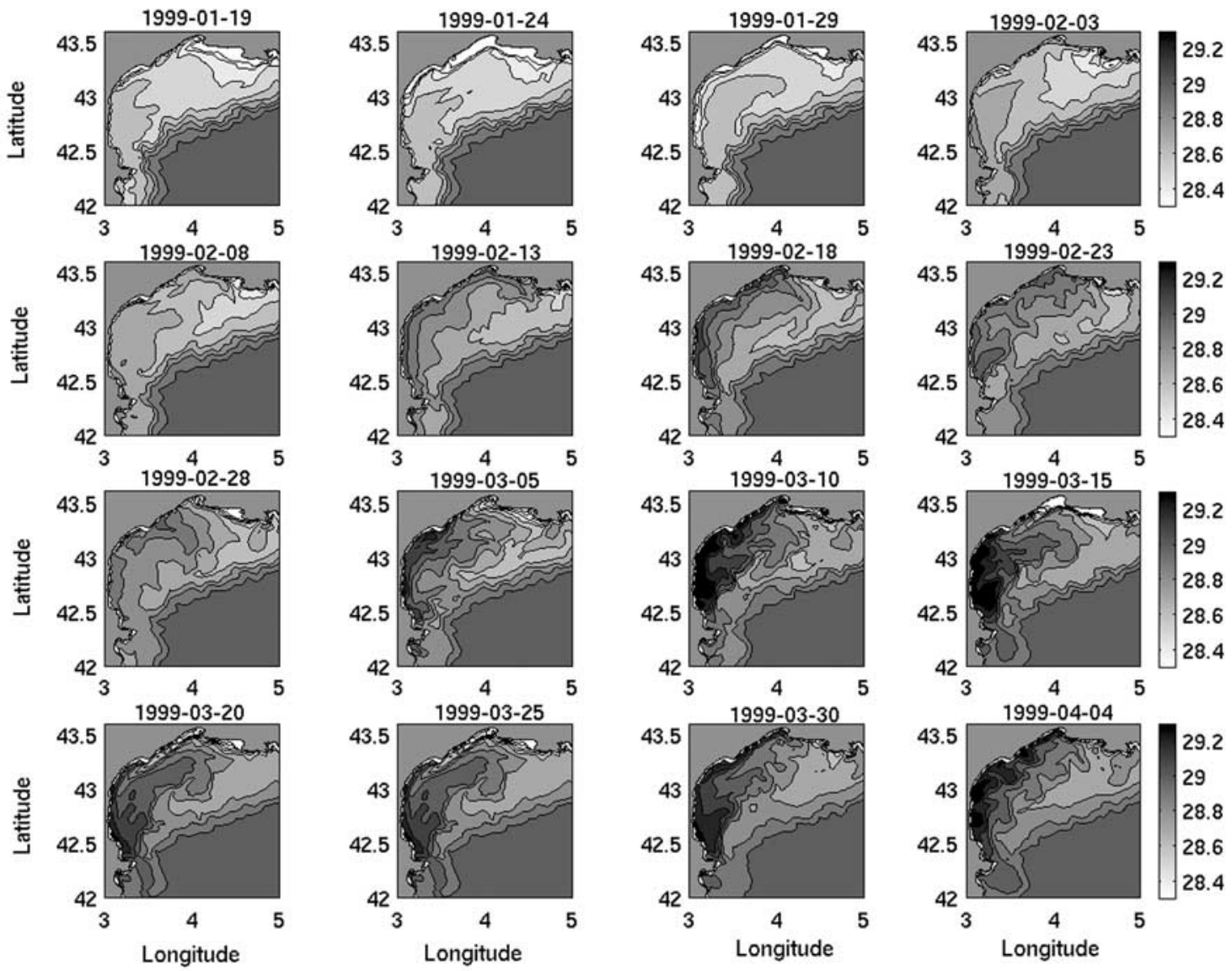

Figure 14. Time evolution of the simulated bottom density from 19 January 1999 to the end of the simulation (4 April 1999).

parameter. The velocity $\overrightarrow{\mathrm{u}}_{\mathrm{B}}$ corresponds to $\overrightarrow{\mathrm{u}}_{\text {Nof }}$ previously described. The velocity $\overrightarrow{\mathrm{u}}_{\mathrm{B}}^{\mathrm{s}}$ has the same magnitude as $\overrightarrow{\mathrm{u}}_{\mathrm{B}}$ but is directed downslope. The velocity $\overrightarrow{\mathrm{u}}_{\mathrm{O}}$ represents the ambient current, which flows above the plume. The velocity $\overrightarrow{\mathrm{u}}_{\mathrm{O}}^{\mathrm{s}}$ has the same amplitude as $\overrightarrow{\mathrm{u}}_{\mathrm{O}}$ and is directed downslope. It is due to the "forced Ekman drainage." The adimensional coefficients $F$ depend on the ratio $\eta=\frac{h}{h_{E}}$ and exhibit the nonlinearity of the process,

$$
\begin{aligned}
\mathrm{F}_{1}= & 2 \sin (\eta) \mathrm{e}^{-\eta}-\sin (2 \eta) \mathrm{e}^{-2 \eta} \\
\mathrm{F}_{2}= & \sin (\eta) \mathrm{e}^{-\eta} \\
\mathrm{F}_{3}= & 1-2 \cos (\eta) \mathrm{e}^{-\eta}+\cos (2 \eta) \mathrm{e}^{-2 \eta} \\
\mathrm{F}_{4}= & 1-\cos (\eta) \mathrm{e}^{-\eta} \\
\mathrm{F}_{5}= & \left(1-\cos (\eta) \mathrm{e}^{-\eta}-\sin (\eta) \mathrm{e}^{-\eta}\right) * 0.5 \\
\mathrm{~F}_{6}= & 1-\cos (\eta) \mathrm{e}^{-\eta}-\sin (\eta) \mathrm{e}^{-\eta}+0.25 *\left(\sin (2 \eta) \mathrm{e}^{-2 \eta}-1\right. \\
& \left.+\cos (2 \eta) \mathrm{e}^{-2 \eta}\right)
\end{aligned}
$$

[34] The four velocities (on the left side of the advectiondiffusion equation) provide information on the interface motion. Specific F ratios can explain the behavior of the plume according to its thickness. Indeed, they highlight the respective role of gravity current and along-slope forcing current. $F_{2} / F_{4}$ is the relative weight of the Ekman drainage compared to the along-slope current entrainment. $\mathrm{F}_{1} / \mathrm{F}_{3}$ corresponds to the relative importance of the cascading movement to the along-slope Nof speed. $\left(\mathrm{F}_{1} / \mathrm{F}_{2}\right) \quad\left(\left\|\overrightarrow{\mathrm{u}}_{\mathrm{Nof}}\right\| /\left\|\overrightarrow{\mathrm{u}}_{0}\right\|\right)$ shows the relation between the cascading by gravity and the downslope motion induced by the Ekman drainage. For a plume thicker than one half the Ekman depth $\left(h>h_{E} / 2\right)$, the along-slope translation, due to $\overrightarrow{\mathrm{u}}_{\mathrm{O}}$, prevails on the Ekman drainage (downslope direction). The Nof speed (along-slope) prevails on the cascading, because friction effects become less important. Consequently, for a thick plume, along-slope motion dominates. On the other hand, a thin plume tends to go downslope due to cascading or Ekman drainage. Another ratio permits us to distinguish the importance of these last two effects on the plume: for $\left\|\overrightarrow{\mathrm{u}}_{\mathrm{Nof}}\right\|=\left\|\overrightarrow{\mathrm{u}}_{0}\right\|$, if $\mathrm{h}<\mathrm{h}_{\mathrm{E}} / 2$ (thin plume), cascading prevails on drainage.

[35] Thanks to this model, SH97 investigated the behavior of a dense plume over different shapes of bottom. Above a flat bottom, the diffusion-like spreading induces a weak propagation. On a sloping bottom, the adding of a downslope component permits us to enhance the propagation of the plume. Two persistent conclusions arise from all their experiences: (1) an entrainment $w_{\text {ent }}$ enhances the propagation of the plume, and (2) an interior flow with shallow waters on its right accelerates downslope motion. The study of a 3-D varying plume shows that each part of the plume 


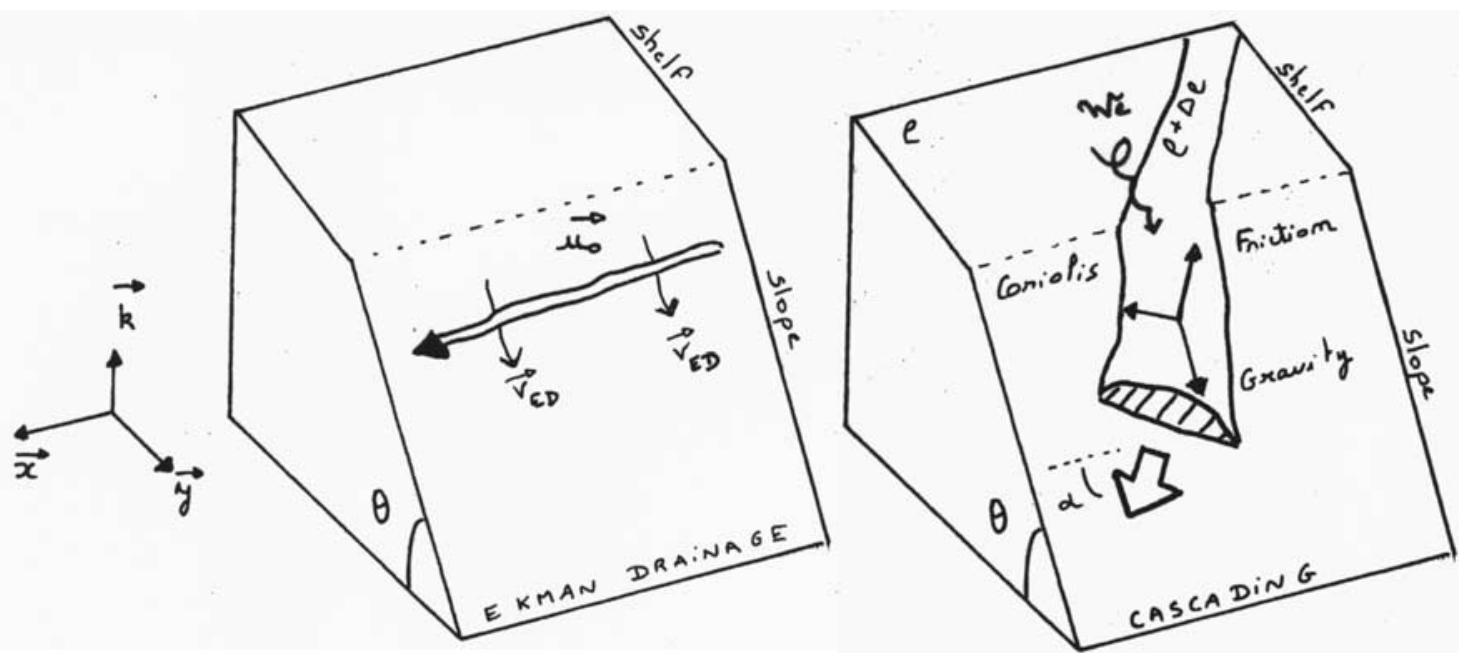

Figure 15. Schematic views of (a) the current-forced Ekman drainage and (b) the dense water spreading over a bottom slope.

propagates with its own speed, resulting in a plume distortion. The following sections present two cases of dense plume that occurred during the 1998-1999 wintertime. They are studied with the former theory.

\subsection{Application to the 1998-1999 Wintertime}

[36] During the period of the MOOGLI3 experiment, a modeled dense plume (called "plume 1" in Table 3) is analyzed from a dynamical point of view thanks to the theory described above (table 3). By looking at $3.18^{\circ} \mathrm{E}$ (Figure 12b), the plume thickness is about $10 \mathrm{~m}$. The
Ekman depth is calculated by the 3-D model and equal to $8 \mathrm{~m}$ at this place in the plume. Thus $\eta=1.25>0.5$, which means that the plume can be considered here as a thick one. According to SH97 theory, it means that the plume should be very sensitive to an along-slope ambient current. However, there is no such current in this case. Consequently, the $\mathrm{F}_{1} / \mathrm{F}_{3}$ ratio can be interpreted as follows: the plume movement is more along-slope than cross-slope. The 3-D simulation agrees with this repartition of velocity (see Table 3). The $\mathrm{F}_{1} / \mathrm{F}_{3}$ ratio also gives an idea of the direction of the plume propagation since $\alpha=\mathrm{a} \tan \left(\mathrm{F}_{1} / \mathrm{F}_{3}\right)=33.3^{\circ}$. In
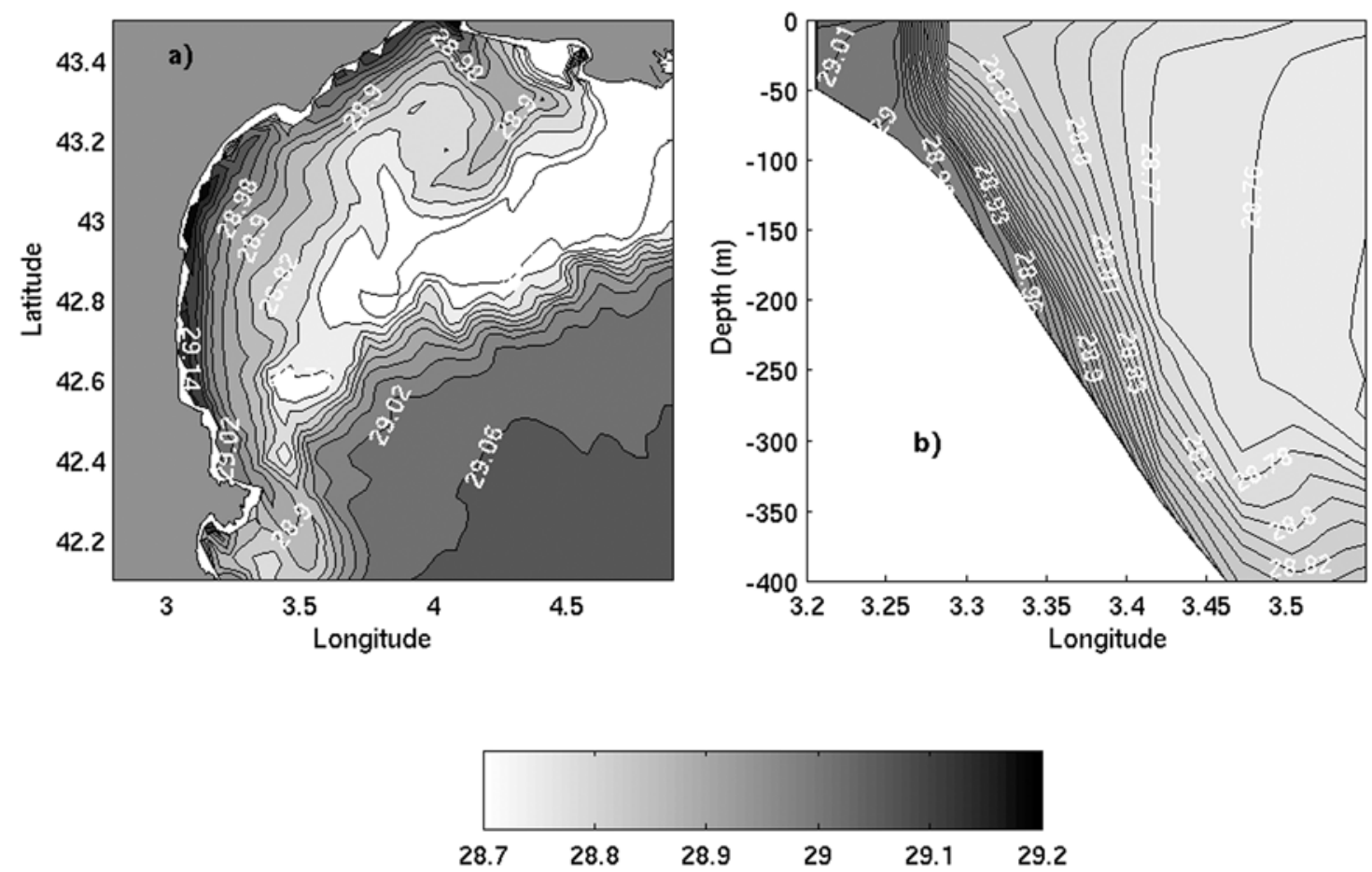

Figure 16. (a) Horizontal contours of $\sigma_{\mathrm{t}}$ at the bottom on 15 February 1999 and (b) vertical section along the $42.36^{\circ}$ parallel at the same time. 
Table 3. Shapiro and Nof's Parameters Calculated for Two Modeled Dense Plumes ${ }^{\mathrm{a}}$

\begin{tabular}{|c|c|c|}
\hline Parameters & Plume 1 & Plume 2 \\
\hline Date & 15 January 1999 & 15 February 1999 \\
\hline Latitude & $42.50^{\circ} \mathrm{N}$ & $42.36^{\circ} \mathrm{N}$ \\
\hline Longitude & $3.18^{\circ} \mathrm{E}$ & $3.34^{\circ} \mathrm{E}$ \\
\hline Depth, m & 57 & 205 \\
\hline$\rho_{\text {plume}}, \mathrm{kg} / \mathrm{m}^{3}$ & 1028.66 & 1028.96 \\
\hline$\rho_{\text {ambient }}, \mathrm{kg} / \mathrm{m}^{3}$ & 1028.56 & 1028.77 \\
\hline Reduced gravity g' (m/s $\left.\mathbf{s}^{2}\right)$ & $9.53 \times 10^{-4}$ & $1.81 \times 10^{-3}$ \\
\hline Slope & $4.89 \times 10^{-3}$ & $1.90 \times 10^{-2}$ \\
\hline Unof $(\mathrm{cm} / \mathrm{s})=g^{\prime} \times$ slope $/ f$ & 4.7 & 34.6 \\
\hline Panache thickness, $\mathrm{m}$ & 10 & 20 \\
\hline Ekman depth, $m$ & 8 & 41 \\
\hline$\eta=H_{\text {plume }} / H_{\text {Ekman }}$ & 1.25 & 0.49 \\
\hline $\mathrm{F}_{1} / \mathrm{F}_{2}$ & $0.495 / 0.272=1.820$ & $0.265 / 0.288=0.919$ \\
\hline $\mathrm{F}_{2} / \mathrm{F}_{4}$ & $0.272 / 0.910=0.299$ & $0.288 / 0.459=0.627$ \\
\hline $\mathrm{F}_{1} / \mathrm{F}_{3}$ & $0.495 / 0.754=0.656$ & $0.265 / 0.128=2.070$ \\
\hline \multicolumn{3}{|l|}{ Ambient along-slope current } \\
\hline $\mathrm{Uo}, \mathrm{cm} / \mathrm{s}$ & - & 30 \\
\hline \multicolumn{3}{|l|}{ Along-slope velocities } \\
\hline $\mathrm{F}_{3}$ Unof & 3.542 & 4.428 \\
\hline $\mathrm{F}_{4} \mathrm{Uo}$ & - & 13.784 \\
\hline Total, cm/s & 3.542 & 18.212 \\
\hline \multicolumn{3}{|l|}{ Across-slope velocities } \\
\hline $\mathrm{F}_{1}$ Unof & 2.325 & 9.167 \\
\hline $\mathrm{F}_{2} \mathrm{Uo}$ & - & 8.649 \\
\hline Total, cm/s & 2.325 & 17.816 \\
\hline \multicolumn{3}{|l|}{ 3-D modeled velocities, $\mathrm{cm} / \mathrm{s}$} \\
\hline along-slope & 6 & 29 \\
\hline across-slope & 4 & 70 \\
\hline
\end{tabular}

${ }^{\mathrm{a} B}$ Boldface denotes main results.

the 3-D simulation, this propagation angle can also be computed via

$$
\alpha=\operatorname{atan}\left(\frac{\text { cross }- \text { slope velocity }}{\text { along }- \text { slope velocity }}\right)=33.7^{\circ} .
$$

Despite this excellent agreement in the direction of propagation, the difference in velocities shows that the 3 -D modeled cascading process is not completely described by the simple SH97 theory. A first explanation can be found in the bottom topography, which is more complex in the 3-D model than in the SH97 model. Indeed, the nonlinear shape of the real bathymetry could break the geostrophy constraint and induce a more intense downslope motion. This break of the geostrophy constraint, previously induced by friction or by ambient current, could also be generated by abrupt variations of the bottom slope, such as submarine canyons. The canyon sidewalls can, in fact, eliminate the Coriolis force component and enhance the downslope motion due to the buoyancy forces [Hill, 1998]. Chapman and Gawarkiewicz [1995] have also studied the role of submarine canyons on dense plume export. They have shown that canyons steer dense waters offshore, and that a plume moves faster in a canyon than eddies on a uniformly sloping shelf. Furthermore, in a nested modeling of the western part of the GoL, with a higher spatial resolution $(1.5 \mathrm{~km})$, the WIW plume exhibits a stronger export of WIW toward the open ocean, and its shape is more confined in the Cap Creus canyon.

[37] In mid-February, new WIW plumes occur over the GoL. Looking at the results of the simulation on 15 February, near Cap Creus, one can find evidence of a strong cascading of WIW. A vertical section of modeled density (Figure 16b) allows us to evaluate the main SH97 parameters at the head of the plume (plume 2, Table 3 ). This plume is considered as a "thin plume" as $\eta=0.49$. Then its down-slope movement prevails on the along-slope displacement. Indeed, the F coefficients (Table 3) show that the cascading is two times greater than the along-slope velocity component induced by gravity. An ambient current flows above the plume and leads to an exportation of the same order than the cascading. The $\mathrm{F}$ ratio gives a propagation angle for this plume equal to $44.4^{\circ}$. It is more important than the one of plume 1 . The cross-slope component reaches $0.7 \mathrm{~m} / \mathrm{s}$ in the $3-\mathrm{D}$ simulation, but is only about $0.2 \mathrm{~m} / \mathrm{s}$ with the SH97 theory. This discrepancy can be explained by a velocity acceleration at the vicinity of Cap Creus. In fact, a kind of "Venturi effect" occurs, accelerating the southward component of the velocity. Hence the bottom plume presents a strong local exportation due to a coastline bathymetry effect. Despite this phenomenon, the simple theory does not explain completely the WIW exportation, hence pointing to the role of other local processes in the down-slope movement of this shelf dense water.

[38] Moreover, the location of the two previous cases of dense water sliding and cascading seems to be a consistent feature in the WIW exportation offshore. Indeed, by looking at the trajectories followed by modeled Lagrangian drifts (results not shown) during this winter, one can, in fact, notice that all of them leave the GoL at the same location, near Cap Creus. This pattern confirms Bethoux et al.'s [2002] observations, which showed that cascading of dense water mostly occurs in the southwestern part of the GoL. Atmospheric fluxes are, in fact, stronger in this part of the GoL than in any other part. Nevertheless, the simulation shows that dense water formation also appears in the northern part of the shelf. However, the Rhône freshwater 
probably acts as a physical barrier for these waters, preventing them from reaching the edge of the shelf (Figures 14 and 16).

\section{Conclusion}

[39] The 3-D simulation of winter hydrodynamics during the MOOGLI3 period reaches a correct representation of the real oceanic situation despite the fact it does not assimilate data. The modeled circulation patterns and the water masses positions qualitatively agree with the in situ measured data. This numerical simulation gives a real opportunity to analyze WIW formation, which is a process very hard to observe. Induced by the strong atmospheric events, especially during late January, February, and March, this dense water formation occurs on the whole shelf. WIW spreads over the shelf as dense plumes that flow over the bottom toward higher depths and cascade over the shelf break. Two bottom plumes have been analyzed in their offshore exportation at the southwestern part of the shelf break. Shapiro and Hill's [1997] theory is used to understand the main mechanisms of these plumes. In both cases, the analysis shows that the plume down-slope motion is only partially explained by the friction effects and Ekman drainage. Local effects, such as the sharp bottom topography or coastline shape, constitute other non-negligible forcings of the downslope motion. Indeed, the presence of the Lacaze-Duthiers canyon and Cap Creus in the study area probably cause the breaking of the geostrophic constraint. Thanks to this 3-D simulation, the total amount of WIW formed during the 1998-1999 winter over the GoL's shelf has been roughly evaluated to $500 \mathrm{~km}^{3}$. Finally, it was proved that the WIW formation is strongly linked to the intense winter atmospheric events, which occur above the Gulf of Lions.

\section{Appendix A}

[40] The initialization method is based on the linearized model equations. However, using the full set of equations and variables of the model would lead to solution of a large linear equation system. Following Estournel et al. [2003], the size of system is then reduced, thanks to a set of approximations. First, the horizontal pressure gradient, $\nabla_{\mathrm{H}} \mathrm{p}$, is written, separating its vertical and horizontal dependences,

$$
-\nabla_{\mathrm{H}} \mathrm{p}=-\mathrm{R}(\mathrm{z}) \nabla_{\mathrm{H}} \mathrm{p}_{\mathrm{S}}
$$

where $\nabla_{\mathrm{h}} \mathrm{p}_{\mathrm{S}}$ is the surface pressure gradient and $R(z)$ can be considered as a dimensionless representation of the vertical shear of the geostrophic current. Similarly, the horizontal components of the current are given by

$$
[\mathrm{u}, \mathrm{v}](\mathrm{x}, \mathrm{y}, \mathrm{z})=\frac{\mathrm{R}(\mathrm{z})}{\overline{\mathrm{R}}(\mathrm{x}, \mathrm{y})}[\mathrm{U}, \mathrm{V}](\mathrm{x}, \mathrm{y})
$$

where $(U, V)$ are the components of the transport and $\overline{\mathrm{R}}$ is described as follows:

$$
\overline{\mathrm{R}}(\mathrm{x}, \mathrm{y})=\int_{-\mathrm{h}(\mathrm{x}, \mathrm{y})}^{0} \mathrm{R}\left(\mathrm{z}^{\prime}\right) \mathrm{dz} .
$$

[41] Equations (A2) and (A3) show that $\bar{R}$ is directly related to the current thickness and that its horizontal variations depend strongly on the horizontal variations of the topography $h(x, y)$. Neglecting advective and time variation terms, a set of equations for the components of transport can be obtained from equations (A1) to (A3) and from the vertical integrated equations of motions,

$$
\begin{gathered}
-\mathrm{fV}=-\frac{\overline{\mathrm{R}}}{\rho_{0}} \frac{\partial \mathrm{p}_{\mathrm{S}}}{\partial \mathrm{x}}-\mathrm{ru}_{(\mathrm{z}=-\mathrm{h})}+\vartheta(\mathrm{U})+\frac{\mathrm{U}_{\mathrm{r}}-\mathrm{U}}{\mathrm{T}_{\mathrm{r}}} \\
\mathrm{fU}=-\frac{\overline{\mathrm{R}}}{\rho_{0}} \frac{\partial \mathrm{p}_{\mathrm{S}}}{\partial \mathrm{y}}-\mathrm{rv}_{(\mathrm{z}=-\mathrm{h})}+\vartheta(\mathrm{V})+\frac{\mathrm{V}_{\mathrm{r}}-\mathrm{V}}{\mathrm{T}_{\mathrm{r}}} .
\end{gathered}
$$

[42] The second term on the right-hand side of equations (A4) and (A5) is a linear expression for the bottom friction. The constant $r$ corresponds to a linearized version of the product $C_{d}\left\|\vec{V}_{b}\right\|$ of equation (A1). Here $\vartheta$ is the linear horizontal viscosity operator. The last term on the right-hand side is a restoring term of transport toward a prescribed forcing field $\left(U_{r}, V_{r}\right)$. The timescale, $T_{r}$, is prescribed empirically to 10 days. It permits us to obtain a solution that, at the same time, takes into account the dynamical constraints of the ocean model and looks like the forcing field.

[43] The rigid lid approximation is then used in order to express the transport in terms of a barotropic stream function $\psi$. The pressure gradient terms can be eliminated if the following operators $\frac{\partial}{\partial \mathrm{y}}(\dot{\overline{\mathrm{R}}})$ and $-\frac{\partial}{\partial \mathrm{x}}(\dot{\overline{\overline{\mathrm{R}}}})$ are respectively applied to equations (A4) and (A5) and the resulting equations added. Using equation (A2), we then obtain an equation for $\psi$ only,

$$
\begin{aligned}
& -\frac{\partial}{\partial \mathrm{y}}\left(\frac{\mathrm{f}}{\overline{\mathrm{R}}}\right) \frac{\partial \psi}{\partial \mathrm{x}}+\frac{\partial}{\partial \mathrm{x}}\left(\frac{\mathrm{f}}{\overline{\mathrm{R}}}\right) \frac{\partial \psi}{\partial \mathrm{y}}=\mathrm{r} \frac{\partial}{\partial \mathrm{x}}\left(\frac{\mathrm{R}_{(\mathrm{z}=-\mathrm{h})}}{\overline{\mathrm{R}}^{2}} \frac{\partial \psi}{\partial \mathrm{x}}\right) \\
& +\mathrm{r} \frac{\partial}{\partial \mathrm{y}}\left(\frac{\mathrm{R}_{(\mathrm{z}=-\mathrm{h})}}{\overline{\mathrm{R}}^{2}} \frac{\partial \psi}{\partial \mathrm{y}}\right)-\frac{\partial}{\partial \mathrm{x}}\left(\frac{\vartheta(\partial \psi / \partial \mathrm{x})}{\overline{\mathrm{R}}}\right)-\frac{\partial}{\partial \mathrm{y}}\left(\frac{\vartheta(\partial \psi / \partial \mathrm{y})}{\overline{\mathrm{R}}}\right) \\
& \quad+\frac{1}{\operatorname{Tr}}\left(\frac{\partial}{\partial \mathrm{y}}\left(\frac{\mathrm{U}_{\mathrm{r}}+\partial \psi / \partial \mathrm{y}}{\overline{\mathrm{R}}}\right)-\frac{\partial}{\partial \mathrm{x}}\left(\frac{\mathrm{V}_{\mathrm{r}}-\partial \psi / \partial \mathrm{x}}{\overline{\mathrm{R}}}\right)\right) .
\end{aligned}
$$

Equation (A6) can be numerically solved on the model grid as long as the boundary conditions are properly prescribed,

$$
\left(\mathrm{U}_{\mathrm{r}}, \mathrm{V}_{\mathrm{r}}\right)=\left(-\partial \psi_{\mathrm{obc}} / \partial \mathrm{y}, \partial \psi_{\mathrm{obc}} / \partial \mathrm{x}\right)
$$

An initial state for all the model variables is then deduced from the stream function, solution of equation (A6). First, components of transport are directly given by

$$
(\mathrm{U}, \mathrm{V})=(-\partial \psi / \partial \mathrm{y}, \partial \psi / \partial \mathbf{x})
$$

Horizontal components of the current are given by equation (A5). The surface pressure anomaly, $\delta \mathrm{p}_{\mathrm{s}}$, is deduced from equations (A4) and (A5). Using the $z$ derivative of equation (1) and the hydrostatic assumption, a density anomaly field, $\delta \mathrm{p}$, is given by

$$
\delta \rho=-\frac{\delta \mathrm{p}_{\mathrm{s}}}{\mathrm{g}} \frac{\partial \mathrm{R}(\mathrm{z})}{\partial \mathrm{z}} .
$$


An initial density field may finally be obtained by adding the density anomaly to a vertical background profile, the latter being representative of the mean stratification for the modeled area. Various hypotheses may be used to obtain initial temperature and salinity from density. This will be discussed in the following section.

[44] The numerical schemes, used to solve equation (A6), directly derive from the ones used to solve the equations of the external mode of the ocean model. This forces the initial field to agree with the model dynamics. This is a necessary condition for a short model spin-up. As mentioned earlier, the initial field is also used as a forcing term in the open boundary conditions. Here again, consistency with the model equations and adjustment to the local topography improve significantly the stability of the model solution near open boundaries. Despite the simplicity of equations (A1) to (A9), Estournel et al. [2003] showed that the NC could be rather well represented, especially the strength of the current and the three-dimensional distribution of velocities. Indeed, both are easily controlled through the forcing at the open boundaries and $R(z)$, the parameterization of the vertical shear. However, the choice of a unique vertical profile $R(z)$, for the whole calculation area, limits the realism of the initial state. Obviously, we can expect some spatial variability to occur on the vertical distribution of the current, especially in our case, since we simulate both continental shelf and abyssal circulation. We can see from equation (A6) that the adjustment of the current to the topography constraint depends on the horizontal gradient of $\bar{R}$. Hence, because horizontal variations of $\bar{R}$ are less important for thin currents (equation (A3)), these latter are less constrained by topography. Moreover, Auclair et al. [2003] showed that the intrusion of the slope current on the continental shelf is more likely to occur if $R(z)$ quickly vanishes with depth (the thin current case), while, in the opposite, more barotropic currents $(R(z)=1)$ tend to flow along the shelf break. We can conclude from Auclair et al. [2003] that the interaction of the slope current with the shelf circulation is eventually sensitive to the choice of $R(z)$. The solution that we propose here to improve the above method is to initialize the model with a combination of several solutions of equation (A6), each of them being calculated with a particular parameterization of the baroclinic effect. Let $\left(\psi_{\mathrm{i}}, R_{i}(z), i=1,3\right)$ be a set of three solutions for equation (A6) with their own associated vertical current profile. Without loosing the properties that we focused on (adjustment of the current to the topography constraint), the initial state may now be given by

$$
\left(\psi, \mathrm{u}, \mathrm{v}, \delta \mathrm{p}_{\mathrm{s}}, \delta \rho\right)=\sum_{\mathrm{i}=1, \mathrm{~N}}\left(\psi_{\mathrm{i}}, \mathrm{u}_{\mathrm{i}}, \mathrm{v}_{\mathrm{i}}, \delta \mathrm{p}_{\mathrm{si}}, \delta \rho_{\mathrm{i}}\right)
$$

The objective is to reproduce the spatial variability of the three-dimensional circulation of a region like the Gulf of Lion with a limited number of vertical profiles $R_{i}(z)$.

[45] In the work of Estournel et al. [2003], the boundary condition of equation (A6) was given by a schematic representation of the $\mathrm{NC}$ that seemed in reasonable agreement with previous studies [Millot, 1990; Herbaut et al., 1997]. Practically, Estournel et al. [2003] supposed that the $\mathrm{NC}$ could be seen as a slope current and the boundary stream function was actually indexed to the topography. In the present study, the boundary conditions and restoring terms $\left(U_{r}, V_{r}\right)$ of equation (A6) are provided by the outputs of an OGCM. The latter model is basically a Mediterranean application of the 3-D rigid lid Modular Ocean Model (MOM). We used a simulation of year 1998, which has benefited from a data assimilation scheme developed by $D e$ Mey and Benkiran [2002]. Their modeled circulation for the last week of December (Figure A1) clearly shows the Ligurian branch of the current flowing along the slope and entering into the modeled area through its eastern boundary. This slope current is strengthened by the cyclonic circulation associated with the dense water formation area located in the southern part of the modeling domain. Finally, the NC current flows out of the domain at the western boundary. We choose this circulation to calculate the initial state of the MOOGLI3 simulation. The MOM outputs $\left(u_{r}\right.$, $\left.v_{r}, T_{r}, S_{r}\right)$, interpolated on the ocean model grid, are decomposed on the vertical profiles $R_{i}(z)$. The three current fields obtained can be vertically integrated in order to provide the boundary conditions and the restoring terms $\left(U_{r}, V_{r}\right)^{i}$ of equation (A6),

$$
\left(\mathrm{u}_{\mathrm{r}}, \mathrm{v}_{\mathrm{r}}\right)(\mathrm{x}, \mathrm{y}, \mathrm{z})=\sum_{\mathrm{i}=1,3} \mathrm{R}_{\mathrm{i}}(\mathrm{z}) \frac{\left(\mathrm{U}_{\mathrm{r}}(\mathrm{x}, \mathrm{y}), \mathrm{V}_{\mathrm{r}}(\mathrm{x}, \mathrm{y})\right)^{\mathrm{i}}}{\overline{\mathrm{R}}_{\mathrm{i}}(\mathrm{x}, \mathrm{y})}+\varepsilon_{(\mathrm{u}, \mathrm{v})},
$$

where $\varepsilon(\mathrm{u}, \mathrm{v})$ are the residues of the decomposition. The three $R_{i}(z)$ profiles are given by the following expression:

$$
\left\{\begin{array}{l}
\mathrm{R}_{\mathrm{i}}(\mathrm{z})=\frac{\mathrm{A}}{\mathrm{z}_{\mathrm{i}}} \exp \left(\frac{\mathrm{z}_{\mathrm{b}}}{\mathrm{z}_{\mathrm{i}}}\right) \mathrm{z}+1 \text { for } \mathrm{z}_{\mathrm{b}}<\mathrm{z}<0 \\
\mathrm{R}_{\mathrm{i}}(\mathrm{z})=A \exp \left(\frac{\mathrm{z}}{\mathrm{z}_{\mathrm{i}}}\right) \text { for } \mathrm{z}<\mathrm{z}_{\mathrm{b}} \\
\text { with } \mathrm{A}=\left(\left(1-\mathrm{z}_{\mathrm{b}} / \mathrm{z}_{\mathrm{i}}\right) \exp \left(\frac{\mathrm{z}_{\mathrm{b}}}{\mathrm{z}_{\mathrm{i}}}\right)\right)^{-1}
\end{array}\right.
$$

where $z_{b}$ represents the depth of the surface boundary layer and $z_{i}(i=1,3)$ represents the length scales used to control the thickness of the current. In the surface boundary layer $\left(z_{b}<z<0\right)$, we assume that the geostrophic current is a linear function of depth in agreement with a homogeneous density perturbation (equation (A9)). Under the surface layer, we assume that the geostrophic current decays according to an exponential function of depth. The constant $A$ ensures the continuity of the profile and its $z$-derivative. The value of $z_{b}$ is set to the average of the depth of the surface mixed layer (i.e., approximately $100 \mathrm{~m}$ ) calculated by the OGCM over the model grid. The three vertical profiles (Figure A2) are chosen thanks to an empirical analysis of the OGCM fields. The first length scale $z_{1}(5 \mathrm{~m})$ is small compared with the thickness of the surface boundary layer $z_{b}$. It explains the approximately 100 -m-thick linear $R_{1}$ profile. The projection of the MOM total transport onto this profile corresponds mainly to the weak shelf circulation. The second length scale $z_{2}$ is equal to $220 \mathrm{~m}$, and the projection of the MOM transport on it deals with the slope current (i.e., Northern Current). Finally, the deepest quasihomogeneous profile $\left(z_{3}=6000 \mathrm{~m}\right)$ corresponds to the offshore circulation, associated with the WDMW formation. Thus the projections of the MOM total transport onto these three profiles show that each profile corresponds to a 


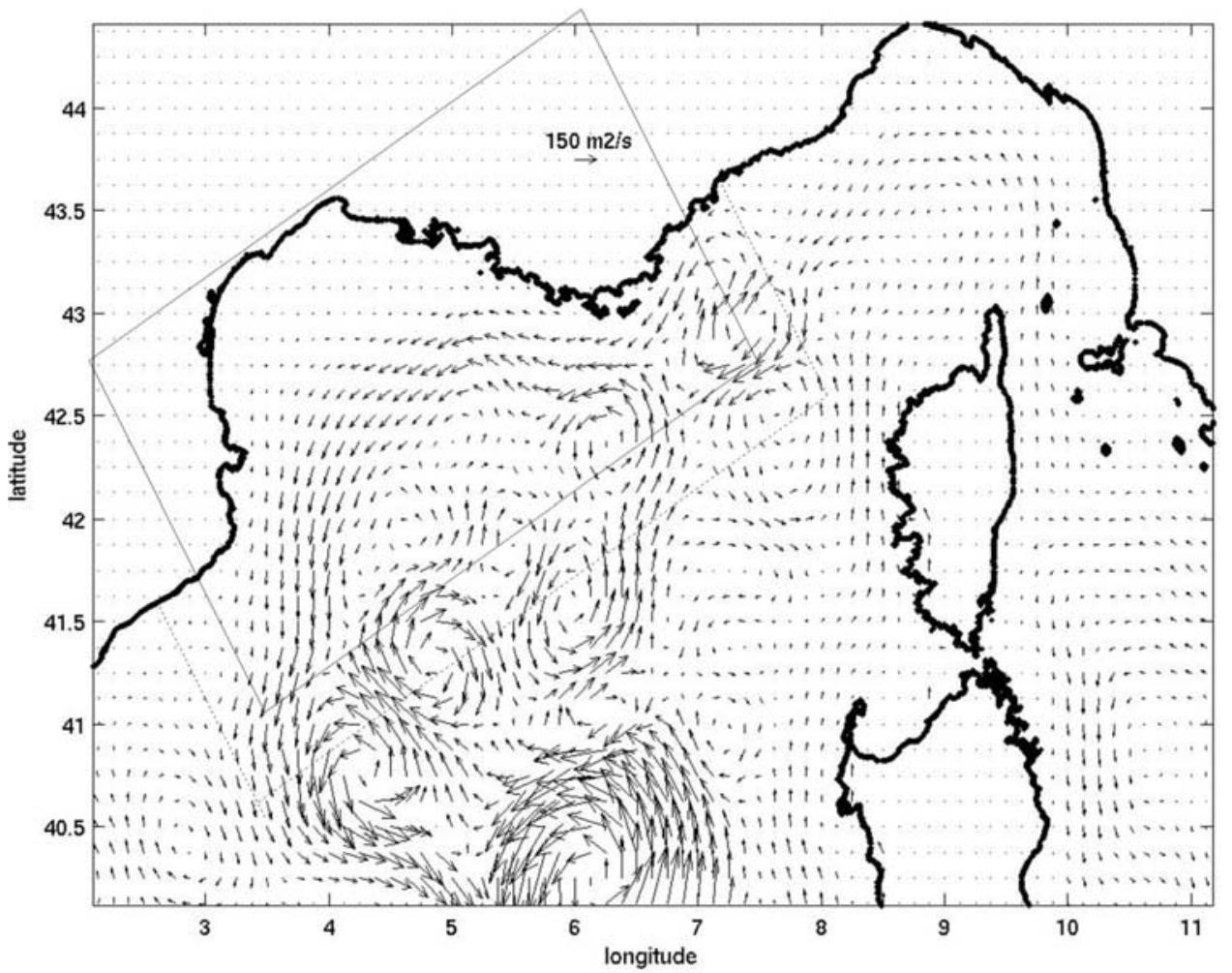

Figure A1. MOM Ocean General Circulation Model's calculated transport for the end of year 1998. The solid line corresponds to the direct modeling area, and the dotted line corresponds to the oceanic limits of the inverse modeling domain.

specific GoL's area. The residues $\varepsilon(u, v)$ of the decomposition are very weak, proving that this decomposition reproduces the total circulation with a reasonable agreement. The three components of the interpolated transport can then be adjusted to the topography constraint if equation (A6) is now solved for each of them separately. The three solutions can be recombined to form the total initial velocity field (equation (A10)).

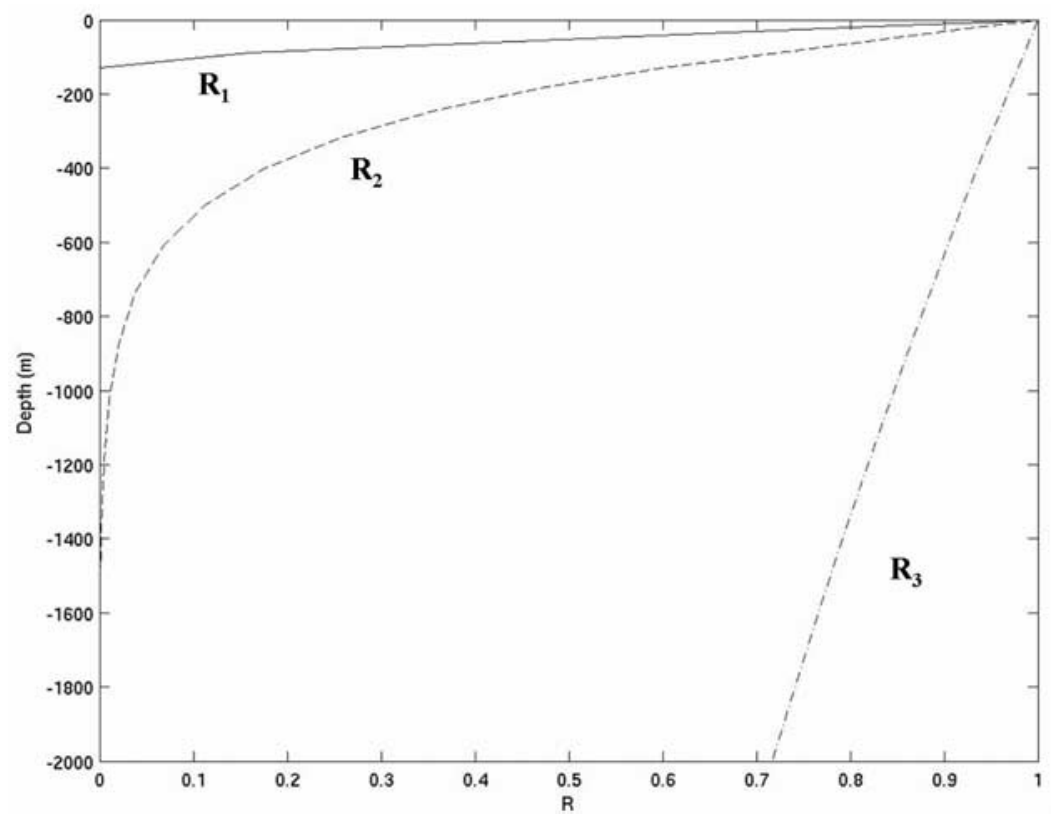

Figure A2. The three $R$ profiles used to project the MOM current signal, corresponding to $R_{1}$, a shallow current (solid line); $R_{2}$, an intermediate current (dashed line); and $R_{3}$, a deep current or quasihomogeneous water column (dash-dotted line). 
[46] The total density field is obtained by adding a background vertical profile to the density anomalies,

$$
\rho=\rho_{\text {ref }}(z)+\sum_{i=1, N} \delta \rho_{i}
$$

where $\rho_{\text {ref }}(z)$, the reference density profile, is the mean density profile of the OGCM field. Now, temperature and salinity have to be obtained from density. The horizontal density variability given by MOM outputs is in the same range as the one observed during the MOOGLI3 cruise. Nonetheless, density anomalies are wrongly distributed between temperature and salinity. This is clear when looking at temperature: Temperature gradients are too strong in the OGCM outputs compared with the MOOGLI3 observations. Using this OGCM temperature as a background field, as suggested by Auclair et al. [2000], would bring unrealistic patterns: a too warm inflowing $\mathrm{NC}$ and an underestimated temperature on the continental shelf. To overcome this problem, we interpolate the MOOGLI3 CTD network on the model grid and use the interpolated temperature field as an initial state. Then the initial salinity is deduced from the latter and from the adjusted density field (equation (A13)) thanks to the equation of state of the model.

[47] Acknowledgments. We thank Météo-France for the atmospheric forcings issued from the Aladin model during the wintertime 1998-1999. We acknowledge the Compagnie Nationale du Rhône for the Rhône and Petit Rhône river 3-hour runoffs. We also thank the DIREN LanguedocRoussillon for those of the Aude, Orb, and Herault rivers. Linear systems described in Appendix A are solved using SCILAB software. Special thanks go to Serge Prieur and Laurent Cabanas, computer scientists, for their technical assistance.

\section{References}

Arakawa, A., and M. J. Suarez (1983), Vertical differencing of the primitive equations in sigma coordinates, Mon. Weather Rev., 111, 34-45.

Auclair, F., P. Marsaleix, and C. Estournel (2000), Sigma coordinate pressure gradient errors: Evaluation and reduction by inverse method, J. Atmos. Oceanic Technol., 17, 1348-1367.

Auclair, F., P. Marsaleix, and C. Estournel (2001), The penetration of the Northern Current over the Gulf of Lions (Mediterranean) as a downscaling problem, Oceanol. Acta, 24, 529-544.

Auclair, F., P. Marsaleix, and P. De Mey (2003), Space-time structure and dynamics of the forecast error in a coastal circulation model in the Gulf of Lions, Dyn. Atmos. Oceans, 36(4), 309-346.

Bethoux, J. P., L. Prieur, and J. H. Bong (1988), Le Courant Ligure au large de Nice, Oceanol. Acta, 9, Special Issue, 56-67.

Bethoux, J. P., X. Durrieu de Madron, F. Nyffeler, and D. Tailliez (2002), Deep water in the western Mediterranean: Peculiar 1999 and 2000 characteristics, shelf formation hypothesis, variability since 1970 and geochemical inferences, J. Mar. Syst., 33-34(C), 117-131.

Blumberg, A. F., and G. Mellor (1987), A description of a threedimensional coastal circulation model, in Three-Dimensional Coastal Ocean Model, Coastal Estuarine Stud. Ser., vol. 4, edited by N. Heaps, pp. 1-16, AGU, Washington, D. C

Bougeault, P., and P. Lacarrere (1989), Parameterisation of orographyinduced turbulence in a meso-beta scale model, Mon. Weather Rev. $117,1872-1890$

Caniaux, G., H. Roquet, and S. Planton (1993), A 3-D mesoscale simulation of the ocean using data from the ATHENA 88 field experiment, J. Mar. Syst, 4(2-3), 197-216.

Chapman, D. C., and G. Gawarkiewicz (1995), Offshore transport of dense water in the presence of submarine canyon, J. Geophys. Res., 100(C7), $13,373-13,387$

Conan, P., and C. Millot (1995), Variability of the northern current off Marseilles, western Mediterranean Sea, from February to June 1992 Oceanol. Acta, 18, 193-205.

Craig, P. D., and M. L. Banner (1994), Modeling wave-enhanced turbulence in the ocean surface layer, J. Phys. Oceanogr., 24, 2546-2559.
Csanady, G. T. (1982), Circulation in the Coastal Ocean, 279 pp., D. Reidel, Norwell, Mass.

De Mey, P., and M. Benkiran (2002), A multivariate reduced-order optimal interpolation method and its application to the Mediterranean basin-scale circulation, in Ocean Forecasting: Conceptual Basis and Applications, edited by N. Pinardi and J. D. Woods, Springer-Verlag, New York.

Estournel, C., V. Kondrachoff, P. Marsaleix, and R. Vehil (1997), The plume of the Rhône: Numerical simulation and remote sensing, Cont. Shelf Res., 17, 889-924.

Estournel, C., P. Broche, P. Marsaleix, J. L. Devenon, F. Auclair, and R. Vehil (2001), The Rhône river plume in unsteady conditions: Numerical and experimental results, Estuarine Coastal Shelf Sci., 53(1), 25-38.

Estournel, C., X. Durrieu de Madron, P. Marsaleix, F. Auclair, C. Julliand, and R. Vehil (2003), Observation and modelization of the winter coastal oceanic circulation in the Gulf of Lions under wind conditions influenced by the continental orography (FETCH experiment), J. Geophys. Res., 108(C3), 8059, doi:10.1029/2001JC000825.

Fieux, M. (1974), Formation d'eau dense sur le plateau continental du Golfe du Lion, in La Formation des Eaux Océaniques Profondes, edited by Colloques Internationaux du C.N.R.S., Cent. Natl. de la Recherche Sci., Verriéres-le-Buisson, France.

Gaspar, P., Y. Gregoris, and J. M. Lefevre (1990), A simple eddy kinetic energy model for simulations of the oceanic vertical mixing: Tests at station Papa and long-term upper ocean study site, J. Geophys. Res., 95, 16,179-16,193.

Geernaert, G. L. (1990), Bulk parameterizations for the wind stress and heat fluxes, in Surface Waves and Fluxes, Current Theory, vol. 1, 336 pp., Kluwer Acad., Norwell, Mass.

Herbaut, C., F. Martel, and M. Crépon (1997), A sensitivity study of the general circulation of the western Mediterranean Sea: 2 . The response to atmospheric forcing, J. Phys. Oceanogr., 27, 2126-2145.

Hill, A. E. (1998), Buoyancy effect in coastal and shelf seas, in The Sea, vol. 10 , chap. 2 , pp. $21-62$, John Wiley, Hoboken, N. J.

Huthnance, J. M. (1995), Circulation, exchange and water masses at the ocean margin: The role of physical processes at the shelf edge, Prog. Oceanogr., 35, 353-431.

Ivanov, V. V., G. I. Shapiro, J. M. Huthnance, D. L. Aleynik, and P. N. Golovin (2004), Cascades of dense water around the world ocean, Prog. Oceanogr., 60, 47-98.

Lapouyade, A., and X. Durrieu de Madron (2001), Seasonal variability of the advective transport of particulate matter and organic carbon in the Gulf of Lion (NW Mediterranean), Oceanol. Acta, 24, 295312 .

Marsaleix, P., C. Estournel, V. Kondrachoff, and R. Vehil (1998), A numerical study of the formation of the Rhône river plume, J. Mar. Syst., 14, $99-115$

MEDOC Group (1970), Observation of formation of deep water in the Mediterranean Sea, Nature, 227, 1037-1040.

Mertens, C., and F. Schott (1998), Interannual variability of deep-water formation in the north-western Mediterranean, J. Phys. Oceanogr., 28, $1410-1424$

Millot, C. (1990), The Gulf of Lion's hydrodynamics, Cont. Shelf Res., $10(9-11), 885-894$.

Nof, D. (1983), The translation of isolated cold eddies on a sloping bottom, Deep Sea Res., Part A, 30(2), 171-182.

Oey, L. Y., and P. Chen (1992), A model simulation of circulation in the northeast Atlantic shelve and seas, J. Geophys. Res., 97, 20,08720,115 .

Pedlosky, J. (1987), Geophysical Fluid Dynamics, second ed., 710 pp., Springer-Verlag, New York.

Person, R. (1974), Un exemple de descente des eaux superficielles du plateau continental dans un canyon du Golfe du Lion, in La Formation des Eaux Océaniques Profondes, edited by Colloques Internationaux du C.N.R.S., Cent. Natl. de la Recherche Sci., Verriéres-le-Buisson, France.

Petrenko, A. (2003), Circulation features in the Gulf of Lions, NW Mediterranean Sea: Summer versus winter conditions, Oceanol. Acta, 26, $323-338$.

Pietrzak, J., J. B. Jakobson, H. Burchard, H. Vested, and O. Petersen (2002), A three-dimensional hydrostatic model for ocean modelling using a generalized topography following coordinate system, Ocean Modell., 4, $173-205$.

Poirel, A., G. Carrel, and J. M. Olivier (2001), Illustration de la complémentarité des chroniques environnementales dans l'étude d'un hydrosytème fluvial: Régime thermique et peuplement piscicoles du Rhône, paper presented at Workshop on Activities in the Catchment Area and Water Quality, Agence de l'eau Rhône Med. and Corse., Lyon, France. 
Raimbault, P. (2000), MOOGLI: Recueil de Données, 271 pp, Lab. d'Océanol. et de Biogéochim., Centre d'Océanol. de Marseille, Marseille, France

Sammari, S., C. Millot, and L. Prieur (1995), Aspects of the seasonal and mesoscale variability of the Northern Current in the western Mediterranean Sea inferred from PROLIG-2 and PROS-6 experiments, Deep Sea Res., Part I, 42(6), 893-917.

Shapiro, G. I., and A. E. Hill (1997), Dynamics of dense water cascades at the shelf edge, J. Phys. Oceanogr., 27, 2381-2394.

Thill, A., S. Moustier, J. M. Garnier, C. Estournel, J. J. Naudin, and J. Y. Bottero (2001), Evolution of particle size and concentration in the Rhône river mixing zone: Influence of salt floculation, Cont. Shelf Res., 21, 2127-2140.

I. Dekeyser and A. Petrenko, Centre d'Océanologie de Marseille, Université de la Méditerranée, Campus de Luminy, F-13288 Marseille Cedex 09, France.

C. Dufau-Julliand and P. Marsaleix, Laboratoire d'Aérologie-Pôle d'Océanographie Côtière, 14 avenue Edouard Belin, F-31400 Toulouse, France. (claire.dufau@notos.cst.cnes.fr) 

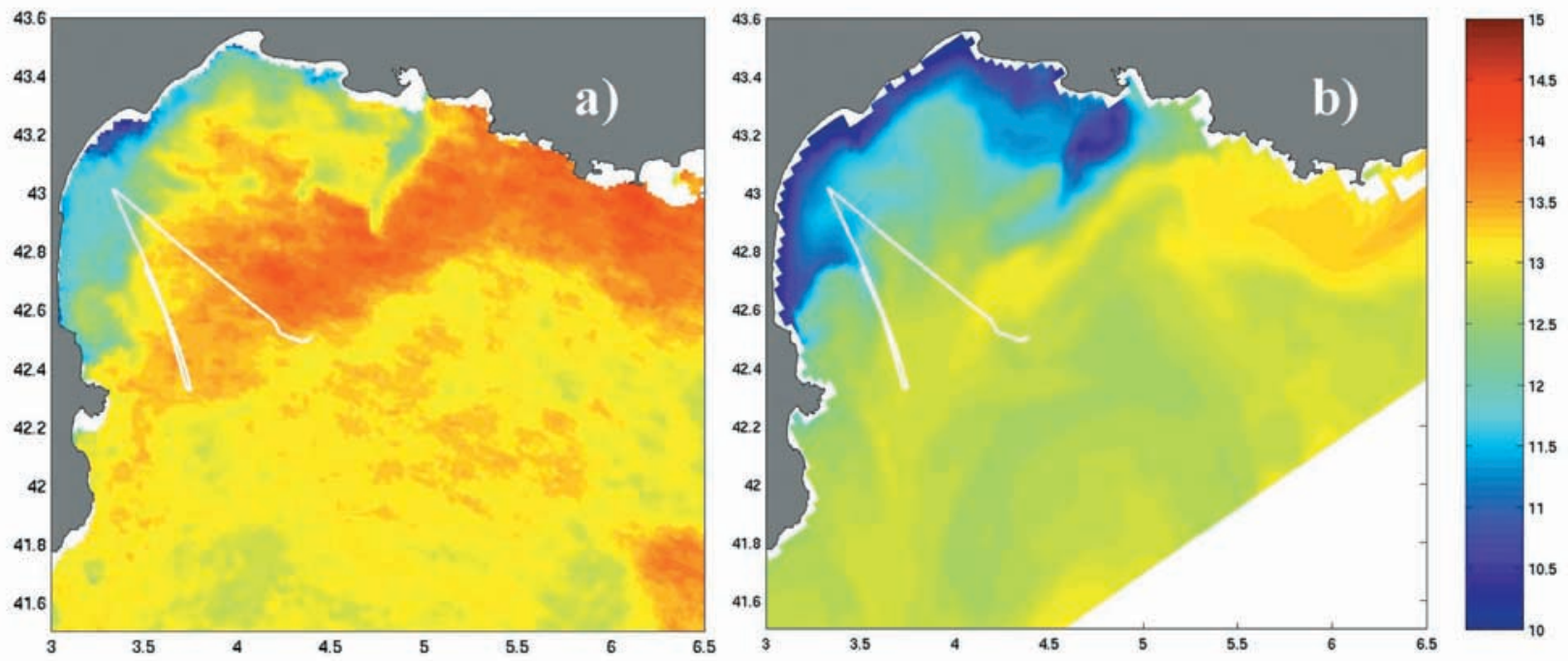

Figures 2a-2b. (a) AHRR sea surface temperature at 0000 hours on the 15 January 1999 (the white line corresponds to the trajectory of the vessel during 24 hours, 12 hours before and after this date). (b) Modeled sea surface temperature by SYMPHONIE at the same time.
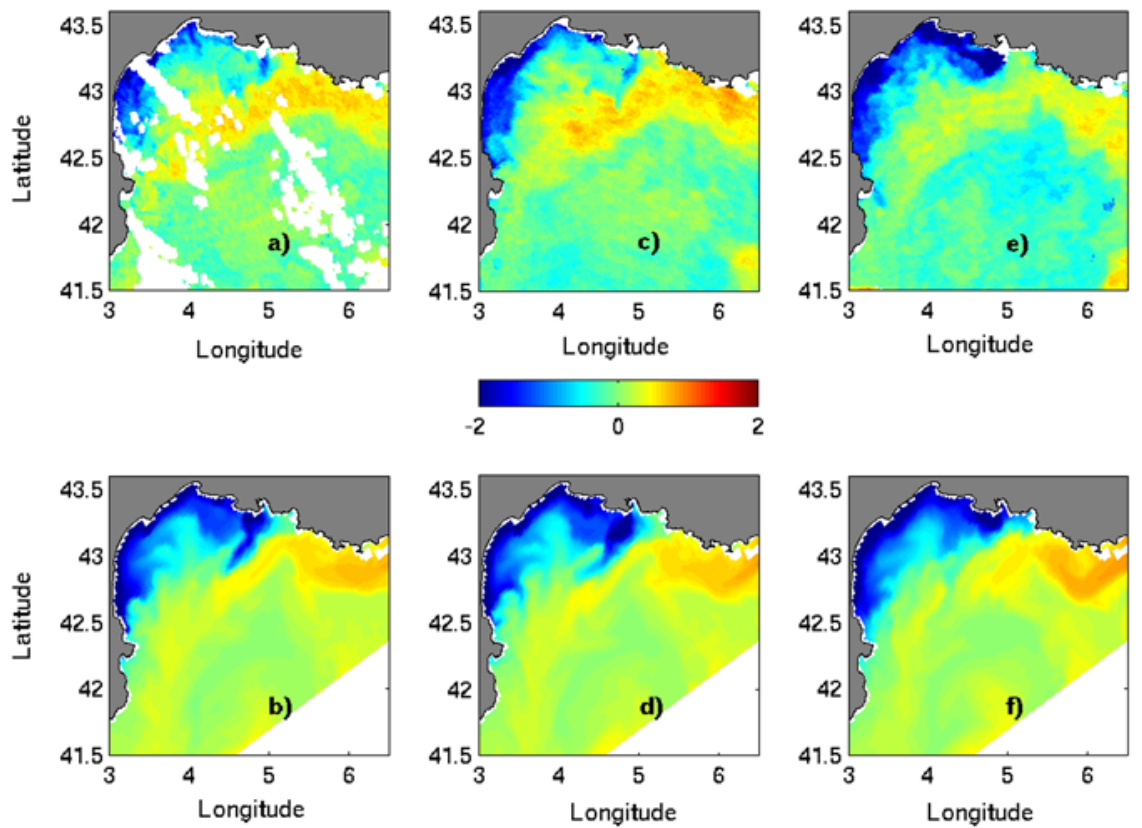

Figure 8. Maps of the sea surface temperature anomaly (the mean temperature signal of each map has been removed): (a, b) 13 January 1999 at 0000 hours, (c, d) 15 January 1999 at 0000 hours, and (e, f) 19 January 1999 at 0000 hours. Figures 8a, 8c, and 8e are AVHRR images; Figures 8b, 8d, and 8f are modeled outputs. 